\title{
Formulation and Evaluation of Linum usitatissimum Mucilage-Based Nanoparticles for Effective Delivery of Ezetimibe
}

\author{
Ume Ruqia Tulain' \\ Arshad Mahmood ${ }^{2}$ \\ Sidra Aslam' \\ Alia Erum' \\ Nadia Shamshad Malik (10 ${ }^{3}$ \\ Ayesha Rashid ${ }^{4}$ \\ Rizwana Kausar ${ }^{5}$ \\ Mohammed S Alqahtani $\mathbb{1 D}^{6}$ \\ 'College of Pharmacy, University of \\ Sargodha, Sargodha, Pakistan; ${ }^{2}$ College of \\ Pharmacy, Al Ain University, Abu Dhabi \\ Campus, Abu Dhabi, United Arab \\ Emirates; ${ }^{3}$ Faculty of Pharmacy, Capital \\ University of Science \& Technology, \\ Islamabad, Pakistan; ${ }^{4}$ Department of \\ Pharmacy, The Women University \\ Multan, Multan, Pakistan; ${ }^{5}$ ILM College of \\ Pharmaceutical Sciences, Sargodha, \\ Pakistan; ${ }^{6}$ Nanobiotechnology Unit, \\ Department of Pharmaceutics, College of \\ Pharmacy, King Saud University, Riyadh, \\ Saudi Arabia
}

Introduction: The aim of current study was to prepare Linum usitatissimum mucilage (LUM) based nanoparticles, capable of encapsulating hydrophobic drug ezetimibe as nanocarriers.

Methods: Solvent evaporation and nanoprecipitation techniques were used to develop nanoparticles by encapsulating ezetimibe in the articulated matrix of polysaccharide fractions. Developed nanoparticles were characterized to determine the particle size, zeta potential, polydispersibility index (PDI), and entrapment efficiency (EE). Morphology and physicochemical characterization were carried out through SEM, FTIR, PXRD and thermal analysis. Saturation solubility and in vitro release studies were also performed. Safety assessment of ezetimibe loaded nanoparticles was evaluated via oral acute toxicity study.

Results: The mean particle size, zeta potential, PDI and EE for emulsion solvent evaporation were $683.6 \mathrm{~nm},-28.3 \mathrm{mV}, 0.39,63.7 \%$ and for nanoprecipitation were $637.7 \mathrm{~nm}, 0.07$, $-27.1 \mathrm{mV}$ and $80 \%$, respectively. Thermal analysis confirmed enhanced thermal stability, whereas PXRD confirmed amorphous nature of drug. Saturation solubility (p-value $<0.05$ ) demonstrated improved solubility of drug when enclosed in linseed nanoparticles. Nanoprecipitation surpasses emulsion solvent evaporation in dissolution test by possessing smaller size. Acute oral toxicity study indicated no significant changes in behavioral, clinical or histopathological parameters of control and experimental groups.

Conclusion: The in vitro release of ezetimibe was augmented by enhancing aqueous solubility through devised nanoparticles. Thus, linseed mucilage could act as biopolymer in the fabrication of nanoparticle formulation. The acute oral toxicological investigations provided evidence that LUMNs were safe after oral administration.

Keywords: linseed mucilage, ezetimibe, nanocarrier, hydrophobic, acute oral toxicity

\section{Introduction}

There has been considerable interest in natural polymers to replace traditional synthetic polymers. Natural mucilage consists of polysaccharides with numerous sugar units, connected to form large molecules. Hydrophilic nature of polysaccharides, proficient stability of the assimilated drug, and enzymatic degradability are exemplary properties that discriminate them from synthetic polymers. Moreover, biocompatibility, non-toxicity, low allergenicity, biodegradability and chemical flexibility allow natural polysaccharides to be used in various applications in biomedical field. ${ }^{1,2}$ Hence, the emerging science provides a technology platform that blends natural polymers and pharmaceutics for the design and development of drug delivery systems under the new concept of Naturapolyceutics. ${ }^{3}$

\footnotetext{
Correspondence: Ume Ruqia Tulain College of Pharmacy, University of Sargodha, Sargodha, Pakistan Tel +92-33l-6668588

Email umeruqia_tulain@yahoo.com

Arshad Mahmood

College of Pharmacy, Al Ain University, Abu Dhabi Campus, Abu Dhabi, United Arab Emirates

Email Arshad.mahmood@aau.ac.ae
} 
Linum usitatissimum mucilage (LUM) is extracted from the hull of linseed by soaking the seeds in distilled water. It is confined to water-soluble as well as water-insoluble fractions. ${ }^{4}$ Principal polysaccharides constituents in mucilage are arabinoxylans and Rhamnogalacturonan, which comprise of different fractions of monosaccharides. ${ }^{5}$ Polysaccharides in linseed mucilage showcase unique and dynamic properties like swelling (pH-dependent), swellingde-swelling ability due to stimuli, reduction of silver and caping capability, these properties were used to make superabsorbent hydrogel and silver nanoparticles for wound dressing and antimicrobial action respectively. ${ }^{6,7}$ Nano assemblies were also prepared using its mucilage and soluble proteins. ${ }^{8}$ by Nasarbadi. Low cost and dynamic characteristics encourage the researchers to use linseed mucilage in novel drug delivery as a green polymer.

Water-insoluble drugs offer plenty of challenges and have low dissolution rates. Lack of substantial solubility demands a system to deliver these drugs to the body while maintaining its biological action and significant availability in the biological environment. To overcome this effect analogs are screened and the pro-drugs approach is considered. But these maneuvers are not thriving as some molecules get deserted in the developmental process or have sub-optimal biological properties like poor bioavailability, deficient dosing eventually indigent patient compliance. ${ }^{9}$

Ezetimibe is an antihyperlipidemic BCS class II drug with poor solubility and poor bioavailability. Different approaches were used to improve water solubility and oral bioavailability of a drug with a better dissolution profile. $^{10,11}$ Among them, Solid lipid nanoparticles were prepared on this concept to improve the in vitro performance of ezetimibe. ${ }^{12}$

During the past four decades, the nanoparticle formulation approach has been employed by the pharmaceutical industry. A distinct internal phase contains an active pharmaceutical ingredient with a physical dimension of $<1$ micron is called nanoparticle. ${ }^{9}$ Biodegradable nanoparticles are often utilized to enhance the therapeutic significance of several water insoluble moieties by increasing solubility, bioavailability, and release time. ${ }^{13}$

The emulsion solvent evaporation method is a commonly employed method of nanoparticle formulation and it is affected by chemical and physical properties of formulations. A single emulsion technique is used for hydrophobic drugs. ${ }^{14}$ In the nanoprecipitation method (NPM), deposition on interface due to solvent displacement by non-solvent is the function of nanoparticle preparation and it is a simple and more feasible method. ${ }^{15}$

In this work, Linseed mucilage was used in the development of polymeric nanoparticle formulations by emulsion solvent evaporation and NPMs and ezetimibe was incorporated. In return, Ezetimibe solubility will be enhanced. Formulations developed with the aim of improved pharmaceutical and pharmacokinetic performance of ezetimibe and green polymer-based more biological and environmental formulation will be advocated. Additionally, emulsion solvent evaporation and NPMs were compared. Furthermore, the influence of different concentrations of polyvinyl alcohol (PVA) on Linum usitatissimum nanoparticles (LUMN) was evaluated.

\section{Materials and Methods Materials}

Ezetimibe of $99.5 \%$ purity was received as a gift from Shazoo Zaka Pvt. Ltd. ${ }^{\circledR}$ (Lahore, Pakistan), The linseed mucilage was extracted from seeds of Linum usitatissimum (LUS) that were cured of the local market of Sargodha (Sargodha, Pakistan), PVA and Tween 80 was obtained from the College of Pharmacy, University of Sargodha (Sargodha, Pakistan) (Sigma Aldrich, Germany), Dialysis membrane was used for dissolution study were purchased from (traders), (Lahore, Pakistan) and Distilled water was taken from Industrial plant of the University of Sargodha ((Sargodha, Pakistan). All other chemicals used in this study were of analytical grade.

\section{Extraction of Mucilage from Linseed}

The LUM was obtained by hot water extraction method. Extraneous materials were removed by picking and sieving of seeds $(200 \mathrm{~g})$. Uncontaminated seeds were soaked in distilled water (1: 9 ratio) at room temperature for 48 hours. Swollen seeds of LUS were passed by 40 mesh sieve later heated at $80^{\circ} \mathrm{C}$ for 30 minutes. The thick exudate was separated by nylon mesh. Defatted mucilage was obtained by $\mathrm{n}$-Hexane ( $\geq 98.0 \%$ purity, Sigma Aldrich, Germany) treatment, the resultant was later washed thoroughly with distilled water (repeated thrice) to collect pure mucilage. LUM pellets were obtained by centrifugation of mucilage at $3500 \mathrm{rpm}$ and the time set was 5 minutes. Dried LUM was triturated to obtain even powder of extract and stored in vacuum desiccators. ${ }^{16}$ A pictorial illustration of each step (A to J) is presented in Figure 1. 

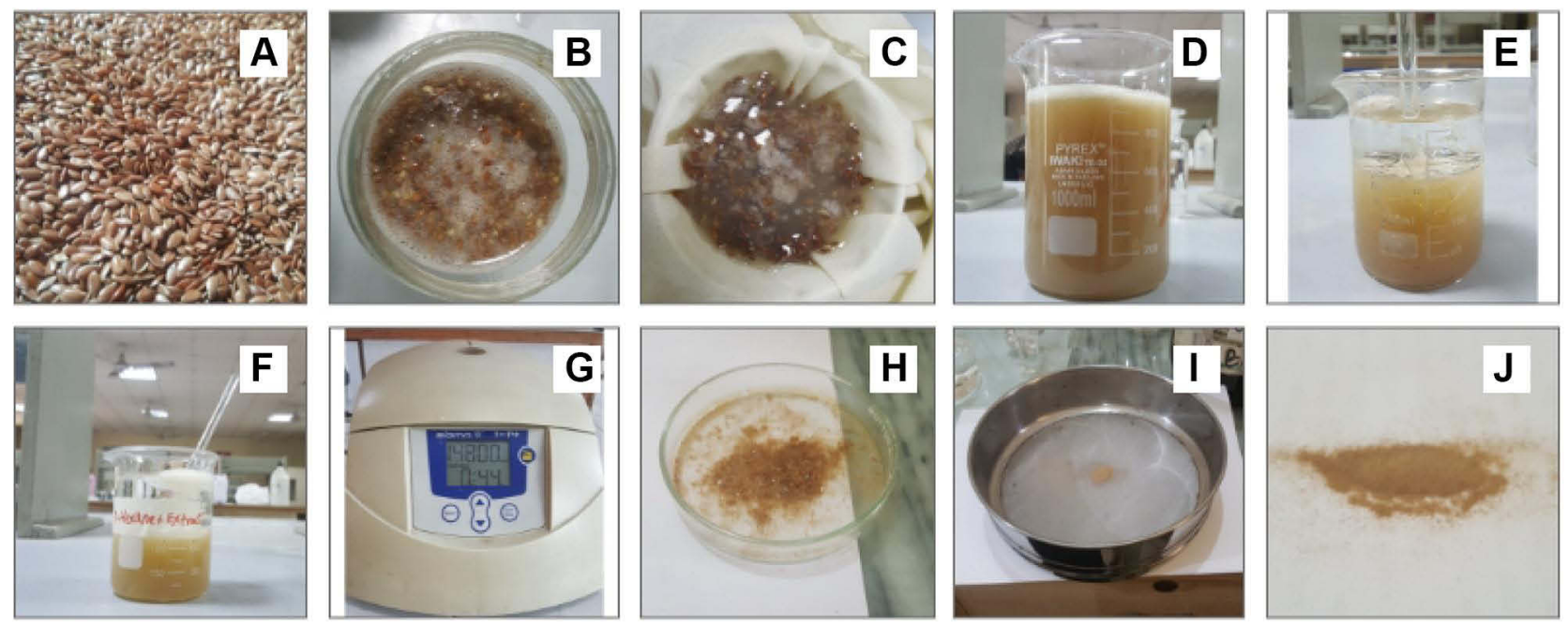

Figure I Diagrammatical representation of stepwise extraction process (A-J) of Linseed mucilage.

\section{Percentage Yield of LUM}

The percentage yield of LUM was calculated by Equation 1 that is given below, and means error was calculated for the process.

$$
\% \text { LUM yield }=\frac{\mathrm{W}(\mathrm{LUM})}{\mathrm{W}(\mathrm{LUS})} * 100 \quad \text { Equation } 1
$$

Where, $\mathrm{W}_{(\text {LUM })}$ is Weight of LUM (g) and $\mathrm{W}_{(\mathrm{LUS})}$ is Weight of LUS seeds (g)

\section{Preparation of Ezetimibe LUMNs by Emulsion Solvent Evaporation Method (ESEM)}

LUMNs loaded with Ezetimibe were prepared by o/w (single emulsion) solvent evaporation technique, adopted from with slight modifications. The organic phase comprised of LUM dissolved in 5\% ethanol and drug in a mixture of ethanol, dichloromethane (DCM), and acetone (1:2:1) were dissolved. The aqueous phase consisted of PVA solution. The organic mixture was emulsified in the PVA solution (aqueous phase) with the help of a homogenizer (company) rotating at $2000 \mathrm{rpm}$ for 15 minutes. Afterward, the solvent mixture was rapidly removed in a rotary evaporator and colloidal suspension of nanoparticles was collected. Furthermore, the resultant nanoparticle suspension was centrifuged at $15,000 \mathrm{rpm}$ for $10 \mathrm{~min}$ to collect nanocarriers. In this study, various concentrations of the polymer and aqueous phase were analyzed while keeping all other parameters constant. Polymer to drug ratio was set as 5:1 and organic mixture to aqueous phase ratio was $3: 1 \mathrm{v} / \mathrm{v}$. Prepared nanoparticles were freeze-dried and stored at $2-8^{\circ} \mathrm{C}$ and further used for characterization. ${ }^{17}$ The composition of different Ezetimibe-LUMNs formulations developed by this method is given in Table 1 and stepwise preparation is presented in Figure 2A.

\section{Preparation of Ezetimibe LUMNs by Nanoprecipitation Method (NPM)}

To make organic phase LUM was dissolved in 5\% ethanol that was filtered later and Ezetimibe was dissolved in $1 \mathrm{~mL}$ of ethanol. The aqueous phase contains distilled water and tween-80 (surfactant). The organic mixture was added drop wise into an aqueous mixture at a rate of $1 \mathrm{~mL} / \mathrm{min}$. Organic to aqueous ratio was set at 3:1. Formed nanosuspension was centrifuged at $15,000 \mathrm{rpm}$ for 10 minutes and lyophilized. Collected Ezetimibe-LUMNs were stored at $2-8^{\circ} \mathrm{C}$ and furthermore characterized. ${ }^{14}$ Formulations prepared by this method are shown in Table 2 and the stepwise preparation of nanoparticles is shown in Figure 2B.

\section{Percentage Yield of the Nanoparticles}

The Ezetimibe-LUMNs were collected. Process yield will determine the obtained yield when compared to the initial amount used to prepare the colloidal nanostructures. Thus the percentage yield was calculated by using Equation $2 .{ }^{18}$

$$
\% \text { yield }=\frac{\mathrm{W}(\mathrm{LUMN})}{\mathrm{W}(\mathrm{X})} \times 100
$$

Equation 2

Where W (LUMNs) is Weight of LUM nanoparticles (mg) and $\mathrm{W}(\mathrm{X})$ is Weight of theoretical initial solids $(\mathrm{mg})$. 
Table I Preparation of Ezetimibe LUMNs by Emulsion Solvent Evaporation Method

\begin{tabular}{|c|c|c|c|c|c|}
\hline Formulations & LUM (mg/mL) & Ezetimibe $(\mathrm{mg} / \mathrm{mL})$ & PVA (\%) & Homogenizer Speed & Time (min) \\
\hline $\mathrm{FI}$ & 0.5 & 10 & 1 & 2000 & 15 \\
\hline $\mathrm{F} 2$ & 1.0 & 10 & 1 & 2000 & 15 \\
\hline F3 & 1.5 & 10 & 1 & 2000 & 15 \\
\hline $\mathrm{F} 4$ & 2.0 & 10 & I & 2000 & 15 \\
\hline F5 & 1.0 & 10 & 0.75 & 2000 & 15 \\
\hline F6 & 1.0 & 10 & 1.5 & 2000 & 15 \\
\hline F7 & 1.0 & 10 & 2.25 & 2000 & 15 \\
\hline F8 & 1.0 & 10 & 3 & 2000 & 15 \\
\hline
\end{tabular}

\section{Determination of Purity of LUM}

Aqueous extract was prepared by dissolving LUM powder in distilled water. Molish's reagent and sulphuric acid was used to identify the presence of carbohydrates. Molish's reagent added in the aqueous extract of linseed mucilage, then sulphuric acid was added. ${ }^{19}$ Amino acids presence in extracted powder was checked by dissolving aqueous extract with Ninhydrin's reagent. ${ }^{20}$

\section{Particle Size and Zeta Potential Analysis}

The hydrodynamic size and polydispersibility index (PDI) and zeta potentials of zeta Polymeric nanoparticles (PNs) were determined via Zetasizer ${ }^{\circledR}$ Nano ZS 90 (Malvern Instruments, UK), operating with a He-Ne laser with water used as a dispersant to eradicate multiple scattering (Refractive index: 1.33). For measurements $\sim 5 \mathrm{mg}$ of Ezetimibe-LUMNs powder was dispersed in $5 \mathrm{~mL}$ of distilled water, vortexed and analyzed at $90^{\circ}$ scattering angle for $30-60 \mathrm{sec}$ at $25^{\circ} \mathrm{C}$ (viscosity of medium $=0.88$, refractive
Table 2 Preparation of Ezetimibe LUMNs by NPM

\begin{tabular}{|l|l|l|l|}
\hline Formulations & $\begin{array}{l}\text { LUM (mg/ } \\
\mathbf{m L})\end{array}$ & $\begin{array}{l}\text { Ezetimibe } \\
(\mathbf{m g} / \mathbf{m L})\end{array}$ & $\begin{array}{l}\text { Tween } \mathbf{8 0}(\%) \\
\mathbf{v} / \mathbf{v})\end{array}$ \\
\hline F9 & 0.5 & 10 & 0.86 \\
FI0 & 1.0 & 10 & 0.86 \\
FII & 1.5 & 10 & 0.86 \\
FI2 & 2.0 & 10 & 0.86 \\
\hline
\end{tabular}

index: 1.59) in a disposable sizing cuvette. ${ }^{21}$ For zeta potentials, an electrical field was applied and movement of charged particles was analyzed by electrophoresis. Zeta potential was measured at $25^{\circ} \mathrm{C}$ and $15^{\circ}$ angle via zeta dip cell, dispersant used was water with a 1.33 refractive index..$^{22}$ Obtained values were articulated as mean values \pm standard deviation (SD) (mean $\pm \mathrm{SD}, \mathrm{n}=3)$.

\section{Entrapment Efficiency of Ezetimibe-LUMNs}

The entrapment efficiency (EE) of Ezetimibe loaded nanoparticles was determined by centrifugation. The prepared
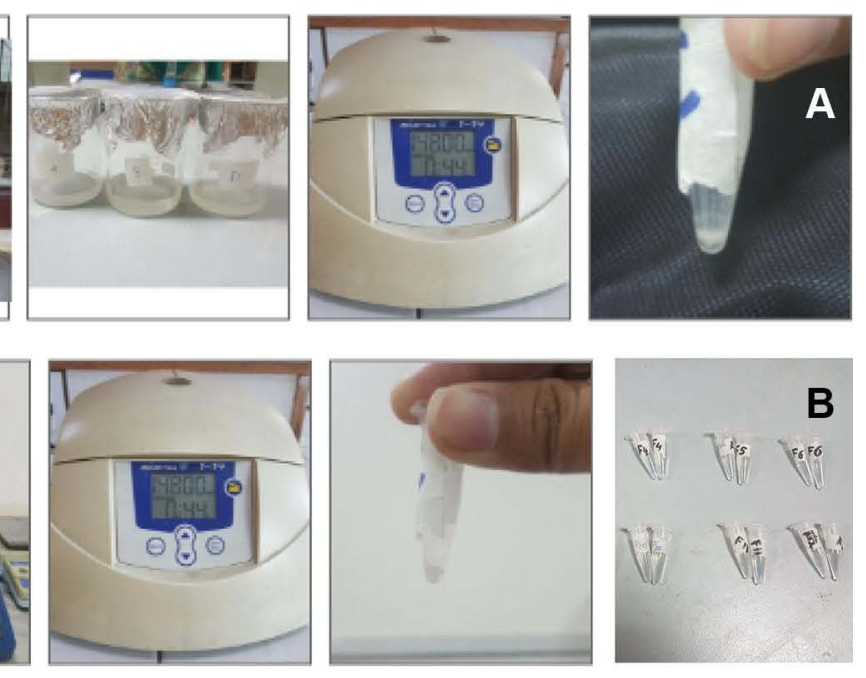

Figure 2 Pictorial representation of stepwise formulation of LUM-Ezetimibe nanoparticles (A) ESEM, (B) NPM. 
colloidal structure was centrifuged at $15,000 \mathrm{rpm}$ for 10 min. The supernatant was collected and dilutions were made with $6.8 \mathrm{pH}$ Phosphate buffer and at $232 \mathrm{~nm}$ the unentrapped drug was calculated. The calibration curve of Ezetimibe was constructed on DD Solver and regressed for quantitative analysis. The experiment was triplicated and mean values were recorded \pm standard deviation (mean $\pm \mathrm{SD}, \mathrm{n}=3)^{23}$

$$
\begin{aligned}
& \text { Entrapment } \\
& \text { Efficiency } \%
\end{aligned}=\frac{\begin{array}{l}
\text { Ezetimibe } \\
\text { (total })
\end{array}-\begin{array}{l}
\text { Ezetimibe } \\
(\text { unentrapped })
\end{array}}{\text { Ezetimibe }(\text { total })} \times 1
$$

Equation 3

\section{Scanning Electron Microscopy}

The shape and surface morphology of PNs was investigated by scanning electron microscopy (SEM) (FEI, Quanta 250) with $10 \mathrm{kV}$ accelerating voltage. The dried samples of emulsion evaporation method and nanoprecipitation were secured on aluminium stub, mounted by a double adhesive tape that was gold/platinum-coated by using a coat sputter. The photographic images were taken at $20 \times$ and $2000 \times$ magnification. $^{24}$

\section{Fourier Transforms Infrared Spectroscopy Instrumental Analysis}

Chemical spectra of Linseed mucilage, Ezetimibe, PVA, tween-80, and Ezetimibe-LUMNs (both methods) were taken by FTIR using IR prestige-21 Shimadzu, Japan to evaluate interactions (physical and chemical). Samples were placed on $\mathrm{KBr}$ disc in the form of pellets via $\mathrm{KBr}$ press machine. Chemical images were acquired by in spectral range $4000-400 \mathrm{~cm}-1$ via initial $\mathrm{KBr}$ background scan. $^{25}$

\section{Thermal Analysis}

The thermal stability of PNs was analyzed by a thermal analyzer (TASDTQ 600, USA). Five milligrams ( $\sim 5 \mathrm{mg})$ of Ezetimibe-LUMNs (obtained from both methods) were weighed and taken in an aluminium pan and analyzed. This sample was scanned at $10^{\circ} \mathrm{C} / \mathrm{min}$ over a range of $50-200^{\circ} \mathrm{C}$ under a dynamic $\mathrm{N} 2 \mathrm{~atm}$ flow rate of $20 \mathrm{~mL} /$ min. An empty cup was taken as a reference. ${ }^{26}$ DSC and TGA curves were recorded. ${ }^{22}$

\section{Powder X-Ray Diffraction}

Powder X-ray diffraction (PXRD) evaluates critical features like crystalline/amorphous nature of Ezetimibe-
LUMNs along with purity of sample preparation. Dried $\sim 10 \mathrm{mg}$ of PNs were observed on x-ray diffractometer (Panalytical, Germany) under a range of Bragg's angle at $40 \mathrm{kV}$ by using $\mathrm{Cu} \mathrm{K} \alpha$ radiation at angular speed of 40 / min between $5^{\circ}$ and $50^{\circ}$ in $2 \theta$ and XRD pattern was reported. ${ }^{27}$

\section{Comparative Solubility Studies}

The saturation solubility of raw Ezetimibe and EzetimibeLUMNs acquired from both emulsion evaporation and NPM were evaluated in $6.8 \mathrm{pH}$ phosphate buffers. Twenty milligrams of each sample were taken in phosphate buffer and continuously shaken at room temperature for 24 hours. After that samples were withdrawn through 0.45 micron filter paper. The resultant filtrate was analyzed by UV-Spectrophotometer at $232 \mathrm{~nm} .^{28}$ The Null hypothesis was devised as: There is no difference of solubility among pure Ezetimibe and Ezetimibe-LUMNs formulations prepared by ESEM and NPM and One-way analysis of variance (ANOVA) $(<0.05)$ was applied to test this hypothesis. ${ }^{29}$

\section{In vitro Dissolution Test}

The dialysis tube method was acquired to determine the in vitro release of Ezetimibe-LUMNs. Accurately weighed $5 \mathrm{mg}$ PNs were introduced into a dialysis tube containing $6.8 \mathrm{pH}$ phosphate buffers that were sealed subsequently, later immersed in $150 \mathrm{~mL}$ of $6.8 \mathrm{pH}$ phosphate buffer. The temperature of the sample containing media was maintained at $37^{\circ} \mathrm{C} \pm 0.5^{\circ} \mathrm{C}$ and stirred continuously at $100 \mathrm{rpm}$ in USP dissolution apparatus II (Pharma test, Germany). During $24 \mathrm{hrs}$ of the dissolution study $5 \mathrm{~mL}$ of sample was wimped out from the outer compartment containing $150 \mathrm{~mL} 6.8 \mathrm{pH}$ buffer and the same amount of fresh aliquots receded back into dialysis tubing at 0.25 , $0.5,1,2,3,4,8,12$ and $24 \mathrm{hrs}$. The collected samples were filtered to separate the undissolved PNs inside the dissolution containers. The dissolved drug amount was quantified via UV spectrophotometer (UV-1700 Pharma spec Shimadzu, Japan) at $232 \mathrm{~nm}$. The dissolution analysis was triplicated for each sample. The release amount was determined by the regression equation and cumulative drug release was measured by using DDSolver. ${ }^{30}$

\section{Evaluation of Drug Release Kinetics}

To assess the release profile of Ezetimibe from LUM nanoparticles model-dependent approach was used. The model dependent approaches such as zero order, First 
order, Higuchi, Hixson-Crowell, and lastly KorsmeyerPeppas were acquired to determine drug dissolution profiles on DD Solver software. Afterward, conclusions of all nanoparticle formulations were drawn for drug releasekinetics. $^{31}$

\section{Statistical Analysis}

The data acquired from all experiments were processed in Microsoft Excel ${ }^{\circledR} 2013$ (Microsoft Corporation, Redmond, USA) and DD Solver. All experiments carried out at least thrice and data were articulated as means \pm standard deviation. Statistical analyses were performed by using an ANOVA to compare saturation solubility of EzetimibeLUMNs formulated by ESEM and NPM and p-values < 0.05 were deemed significant. ${ }^{16}$

\section{Acute Animal Testing}

Linseed mucilage based nanoparticles were evaluated for acute oral toxicity study by using aMaximal Tolerance Dose (MTD) method. The experiments performed were in agreement with OECD guidelines and were verified by the ethics committee of Sargodha University, Sargodha, Punjab Pakistan (Ref. No. 106-2019/PREC). Swiss albino mice (30-35 g) of either sex were purchased from Animal Laboratory Center, Sargodha University. Animals were kept in clean housed facility in a $12 \mathrm{~h}$ light/dark cycle. Animals were divided into two groups $(n=6)$, standard laboratory diet was fed with tap water. The weight variation of mice involved has to be minimal, within $\pm 20 \%$ of mean weight. With an intubation cannula LUMNs were given orally. One group was control and second group was treatment and given colloidal dispersion of LUMNs. General clinical manifestations like activity, diet, weight, signs of illness), and mortality were carried out for two weeks with twice daily protocol. Blood biochemistry and gross necropsy were performed after completion of 14 days and microscopically analyzed via prior conserving in buffered formaldehyde solution (10\%) for 48 hours. Later paraffin fixed, and imaged by hematoxylin and eosin staining. ${ }^{32}$

\section{Results and Discussion \\ Percentage Yield of LUM}

The percentage yield of linseed mucilage is $6.2 \pm 0.2$, obtained from equation 1 by putting mean weight (12.48) of mucilage and initial weight of LUS seeds. LUM yield sturdily confides in extraction conditions. In 2011 extracted linseed mucilage via precipitation by using acetone and menthol and 6.5, 7.0 yields were reported respectively. Linseed mucilage generated 3-9\% yield when ultrasonicated by Fabre et al, in 2015..$^{30,31,33}$ Hot water extraction excludes the use of organic solvent commonly used to precipitate the extract; hence toxicity related to the use of unwanted solvents gets eluded. ${ }^{34}$

\section{Preparation of Ezetimibe LUMNs}

LUM-Ezetimibe nanoparticles were prepared by physical linkage and the illustrative representation of preparation techniques is presented in Figure 3. LUM possesses a distinctive property of shrinking down in ethanol. ${ }^{6}$ This property was employed to entrap Ezetimibe in a polysaccharide network of mucilage. Intermolecular and intra-molecular hydrogen bonding were attributable to the formation of the polysaccharide network. Furthermore, PVA as an emulsifier in ESEM and Tween 80 as a surfactant in NPM assembled on the surface of interfaces to form a monodisperse system of NPs. The milky appearance indicated nanoparticles formation from linseed mucilage. Prepared nanoparticles were pelletized and re-dispersed in distilled water for further evaluation of particle size and percentage yield. Formulations with minuscule size and PDI with finest redispersion capability highest yield was chosen for further studies. ${ }^{35}$

\section{Evaluation of LUM Purity}

Upon addition of Molish's reagent in extract followed by addition of sulphuric acid, the ring was observed at the junction, which confirmed the carbohydrates presence Carbohydrate were marked as present, amino acids and tannins were absent while fats were removed by n-Hexane during extraction process. Hence purity of linseed extract was confirmed. ${ }^{36}$

\section{Evaluation of Ezetimibe LUMNs}

Mean particle size, zeta potential, and mean polydispersibility of LUM-Ezetimibe NPs were determined through dynamic light scattering (DLS) and measurements are tabulated in Table 3. The average particle size of all formulations recorded was ranged between 416-921 $\mathrm{nm}$. The nanosuspension of LUM-Ezetimibe had an average diameter of $683.6 \mathrm{~nm}$ by ESEM and $637.7 \mathrm{~nm}$ NPM in Figure 4A and B. The mean-diameter of LUM suspended nanoparticles was $587.2 \mathrm{~nm}$, it was increased to $637.7 \mathrm{~nm}$ after Ezetimibe loading and aggregation was suspected reason. ${ }^{16}$ A marked rise in size was observed in 


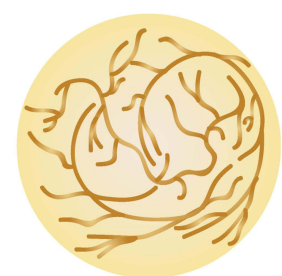

LUM dispersion

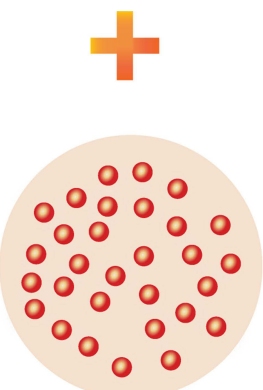

Ezetimibe solution in organic solvents Method A (Ethanol, DCM, Acetone) Method B (Ethanol)

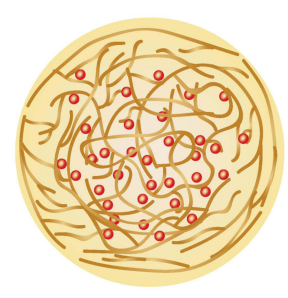

LUM and Ezetimibe (Organic phase)

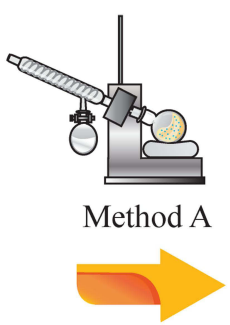

Addition of PVA

(Aqueous phase)

Method

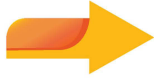

Tween 80 (Aqueous phase)
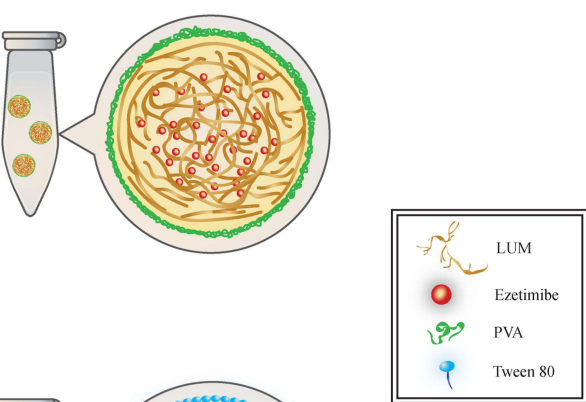

Figure 3 Illustrative representation of preparation methods of LUM-Ezetimibe nanoparticles.

higher concentrations of mucilage. As predicted z-average values were affected by the concentration of mucilage used. It is evident in formulation F1 to F4 and F9 to F12 formulated by NPM mean size of the EzetimibeLUMNs significantly increased when the concentration of mucilage increased with respect to Table $3 .^{37,38}$ A noticeable size reduction was found by the increasing concentration of PVA. ${ }^{39}$ Most formulations were in the range of vascular cut of $(380-780 \mathrm{~nm})$, well separated and homogeneous which portray obliging diffusion into the vascular site. ${ }^{40}$ The zeta potentials were recorded as -15.7 to $-29.5 \mathrm{mV}$. All formulations had negative values of zeta potential. The F3 formulation zeta potential was $-28.3 \mathrm{mV}$ as in Figure $4 \mathrm{C}$, accredited to ionized carboxyl-groups. ${ }^{41}$ F11 batch zeta potential was $-27.1 \mathrm{mV}$ (Figure 4D); the negative charge was the result of surface charge density produced by steric hindrance. ${ }^{41}$ Zeta potential of both techniques was comparable yet the

Table 3 Z-Average, Size Distribution, ל-Potential, Entrapment Efficiency and Percentage Yield of Ezetimibe LUMNs

\begin{tabular}{|c|c|c|c|c|c|}
\hline Formulations & $\operatorname{Size}^{a}(\mathrm{~nm})$ & PDI $^{\mathbf{b}}$ & $\zeta$-Potential ${ }^{\mathrm{c}}(\mathrm{mV})$ & \% E.E & \%yield \\
\hline $\mathrm{FI}$ & $532.1 \pm 3.81$ & $0.25 \pm 0.03$ & $-26.7 \pm 0.6$ & $43.75 \pm 3.6$ & $12.16 \pm 0.25$ \\
\hline $\mathrm{F} 2$ & $516.6 \pm 2.46$ & $0.28 \pm 0.02$ & $-27.2 \pm 0.4$ & $62.5 \pm 4.5$ & $22.3 \pm 0.3$ \\
\hline F3 & $683.6 \pm 4.31$ & $0.39 \pm 0.02$ & $-28.3 \pm 1.20$ & $63.7 \pm 3.6$ & $25 \pm 0.21$ \\
\hline $\mathrm{F} 4$ & $921.5 \pm 3.86$ & $0.45 \pm 0.05$ & $-23.3 \pm 0.9$ & $65 \pm 3.9$ & $28.8 \pm 0.29$ \\
\hline F5 & $651.4 \pm 2.91$ & $0.38 \pm 0.02$ & $-21.1 \pm 2.1$ & $83.75 \pm 4.6$ & $20 \pm 0.25$ \\
\hline F6 & $522.1 \pm 2.77$ & $0.29 \pm 0.03$ & $-18.1 \pm 0.8$ & $82.5 \pm 3.9$ & $23 \pm 0.22$ \\
\hline F7 & $417.5 \pm 2.43$ & $0.23 \pm 0.02$ & $-17.5 \pm 2.3$ & $62.5 \pm 3.7$ & $22.5 \pm 0.27$ \\
\hline F8 & $390.7 \pm 3.42$ & $0.13 \pm 0.02$ & $-15.7 \pm 1.3$ & $56.2 \pm 5.6$ & $24.8 \pm 0.24$ \\
\hline F9 & $416.2 \pm 4.77$ & $0.23 \pm 0.04$ & $-19.9 \pm 0.79$ & $69.4 \pm 3.7$ & $29 \pm 0.2$ \\
\hline FIO & $519.6 \pm 3.67$ & $0.29 \pm 0.06$ & $-21.3 \pm 0.50$ & $72.5 \pm 4.3$ & $31 \pm 0.34$ \\
\hline FII & $637.7 \pm 2.91$ & $0.07 \pm 0.02$ & $-27.1 \pm 1.12$ & $80 \pm 4.9$ & $33 \pm 0.26$ \\
\hline $\mathrm{FI} 2$ & $809.9 \pm 2.30$ & $0.39 \pm 0.02$ & $-29.9 \pm 1.73$ & $81.25 \pm 4.6$ & $35.2 \pm 0.25$ \\
\hline
\end{tabular}

Notes: ${ }^{\mathrm{a}}$ Z-average, ${ }^{\mathrm{b}}$ Polydispersibility, ${ }^{\mathrm{c}}$ Zeta potential. 
A

Size Distribution by Intensity

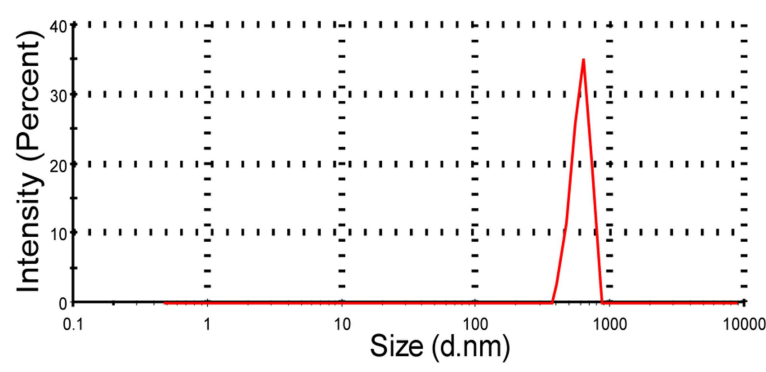

C

Zeta Potential Distribution

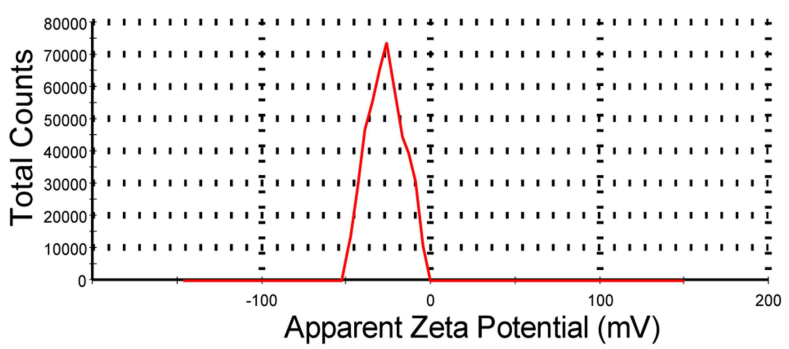

$\mathbf{E}$

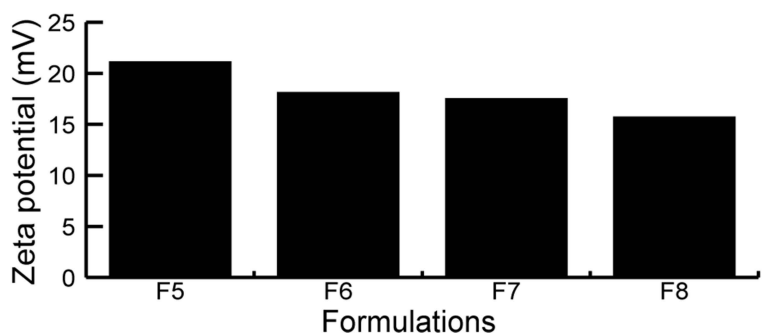

B

Size Distribution by Intensity

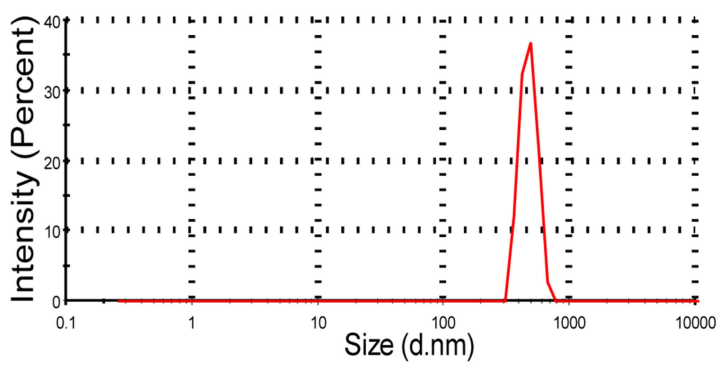

D

Zeta Potential Distribution

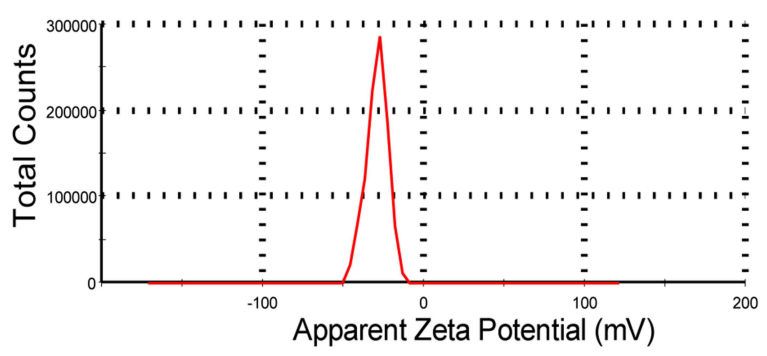

$\mathbf{F}$

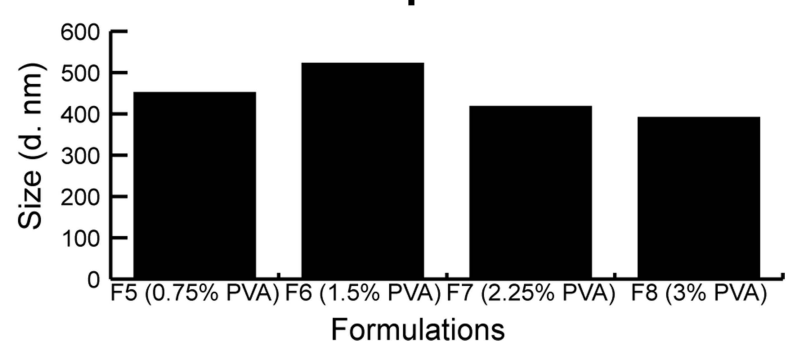

Figure 4 (A) Size distributions of F3 formulation (B) Size distribution of FII formulation (C) Zeta potential of F3 formulation (D) Zeta potential of FII formulation (E) Zeta potential of F5, F6, F7 and F8 formulations (F) Particle size of F5, F6, F7 and F8 formulations.

emulsion solvent evaporation method showed good outcome (Figure 4). Furthermore, the $\zeta$-potential analysis helped to find long term stability of LUMNs, as PNs showed higher zeta potential is negative (-) value for all batches. This verified particle stability due to the presence of repulsive forces which prevents coalescence of nanoparticles with time waning. In Linseed polysaccharide loaded with docetaxel LP-DTX NPs $-31 \mathrm{mV}$ zetapotential was reported by Haseeb et al attributable to carboxylic group ionization on the surface of NPs. ${ }^{16}$ Formulations prepared by ESEM showed lower zetapotentials due to the shielding effect on the charged surface. PLGA nanoparticles have $-45 \mathrm{mV}$ zeta potential. ${ }^{42}$ decrease in $\zeta$-potential of amphiphilic polymer-coated PLGA nanoparticles was observed by Redhead in 2001 and PLGA nanoparticles layered with PVA also exhibited lower zeta-potential. ${ }^{39,43}$

PDI of Ezetimibe LUMNs was appeared to be under 0.45 on the PDI. F11 formulation with $0.07 \pm 0.02$ PDI exhibited monomodal polydispersibility. PDI is the index of variation, Ezetimibe LUMNs displayed good particle size distribution which points toward potential stable candidates of drug delivery. ${ }^{44}$

The percentage yield of Linseed mucilage based nanocarrier formulations was estimated via equation 1 and reported in Table 3. The concentration of polymer played its role in the final yield of the product, as the concentration of polymer was higher in F4 and F12 formulations so they manifested a greater percentage yield of $28.8 \pm 0.29$ and $35.2 \pm 0.25$ respectively. Due to the direct relation 
between mucilage concentration and \%age yield, when polymer amount is increased, the percentage yield also escalates. $^{45}$

For measurement of the actual amount of Ezetimibe present in NPs dilutions were made in $6.8 \mathrm{pH}$ buffer for determination of EE. Details of $\mathrm{EE}$ are present in Table 3 owing to be $43.75 \pm 3.6$ to $83.75 \pm 4.6$. The amount of mucilage used has a definite effect on EE, as it increases with respect to an increase in LUM concentration. The presence of emulsifying agent and surfactant also affect the efficiency of nanoparticles to entrap drug. 17

\section{Influence of PVA Concentration on Pharmaceutical Properties of Ezetimibe LUMNs}

A descending behavior in Ezetimibe LUMNs size from $651 \pm 2.9$ to $390.7 \pm 3.42$ was observed as a result of an increase in concentration in Table 3 when nanoparticles prepared by emulsion ESEM. Higher concentrations of PVA, when used as an emulsifying agent, reduced particle size in Figure 4F markedly because of additional PVA presence at the interface. ${ }^{46}$ The density of the formed emulsion was increased due to higher concentration which augmented shear stress and further hindered particles to aggregate. As a result, smaller size particle with good particle distribution was observed. ${ }^{47}$ On the other hand EE of LUM-Ezetimibe nanoparticles decreased due to the smaller size of NPs. ${ }^{17} \zeta$ potential also became under the influence of PVA concentration as it decreased with an increase in concentration. Residual PVA plays an important role in the extraneous phase formulation, in lower concentration (F5) PVA is $0.75 \%$ and -21.1 zeta potential which decreased to -15.7 in F8 as shown in Figure 4E due to uncapped carboxylic group as a result lower shielding effect. $^{39}$ A higher concentration of PVA has a propensity to be hydrophilic on the hydrophobic core. ${ }^{43}$

\section{Fourier Transforms Infrared Analysis}

Fourier transforms infrared (FTIR) spectrometric analysis was performed to observe the compatibility of mucilage, drug, PVA, and tween-80, additionally, the chemical structure of drug was evaluated, and confirmation of developed Ezetimibe LUMNs. Overlays of FTIR spectrum of Linseed mucilage (LUM), Ezetimibe, PVA, Tween-80, drug-loaded nanoparticles and unloaded nanocarriers developed by both methods of ESEM and NPM are depicted in Figure $5 \mathrm{~A}$ and $\mathrm{B}$, respectively.
The major Stretching frequencies of LUM-Ezetimibe NPs reflect the presence of LUM functional peaks of OH (3332.99 cm-1), CH (2856.59 cm-1) and COO(1685.79 cm-1), COH (1112.93 cm-1) and COC (glycosidic linkage) $1037.70 \mathrm{~cm}-1$ at were observed by both techniques of preparation. ${ }^{16}$ Arabinoxylan and rhamnogalacturonan are principal constituent polysaccharides. These spectral study results confer the presence of highly branched polysaccharide of LUM containing galactose, rhamnose, galacturonic acid, xylose and fucose, which were in agreement with relevant spectral fingerprint peaks of Quin, Emaga and Oomah et al, findings. ${ }^{47-50}$ Pure Tween $80(\mathrm{C}=\mathrm{C}$ at $1508.33 \mathrm{~cm}-1$ and $\mathrm{C}-\mathrm{C} 954 \mathrm{~cm}-1)$ and PVA presence in unloaded nanocarriers were marked by $\mathrm{CH}$ and $\mathrm{C}-\mathrm{C}$ peaks with stretching frequencies of $2927.94 \mathrm{~cm}-1$ and $947.05 \mathrm{~cm}-1$ which are different from their individual FTIR plot. This deviation inferred their contributional relation due to the inter linkage of PVA and LUM due to the synthesis of NPs.

The characteristic peak of Ezetimibe at $1213.23 \mathrm{~cm}-1$ of $\mathrm{CN}$ bond, $\mathrm{CF}$ peak signal mark presence at $1371.39 \mathrm{~cm}-1$ on spectra, other stretching vibrations of $\mathrm{C}=\mathrm{C}, \mathrm{C} 00$ - and $\mathrm{CH}$ bonds was observed at $1510.26 \mathrm{~cm}-1,1710.86 \mathrm{~cm}-1$ and $2885.51 \mathrm{~cm}-1$ respectively (Figure 5A and B). The characteristic IR band of Ezetimibe in NPs is shown in Figure 5 Drug peaks at $1230.58 \mathrm{~cm}-1$ and $1246.02 \mathrm{~cm}-1$ showed CN stretching vibrations, $\mathrm{C}=\mathrm{C}$ at $1506.41 \mathrm{~cm}-1$ and $1510.26 \mathrm{~cm}-1, \mathrm{CH}$ at $2926.01 \mathrm{~cm}-1$ and $3012.81 \mathrm{~cm}-1$ confirmed principal absorption peaks. The spectra do not show any shift in drug peak, which infers that the drug and other formulation excipients showed no interaction chemically in the fabricated formulations when prepared by both techniques. ${ }^{51}$

\section{Thermal Analysis of Ezetimibe LUMNs}

Thermal analysis was carried out and comparative TGA and DSC thermographs of pure drug, LUM, unloaded LUMNs, and Ezetimibe LUMNs fabricated by ESEM and NPM were taken to evaluate crystalline properties and thermal stability. This analysis, on the other hand, acts as a primary tool for gaining information about the formation of a new form. DSC curve of pure drug Ezetimibe, (A) DSC of nanocarriers prepared by ESEM, (B) DSC of nanocarriers prepared by NPM is shown in Figure 6. DSC curve of pure drug Ezetimibe presented a distinctive endothermic peak at $165.4^{\circ} \mathrm{C}$, implying crystallinity of the drug sample. This endothermic peak's onset was at $163^{\circ} \mathrm{C}$ and recovery at $169^{\circ} \mathrm{C}$ and a sharp 
A

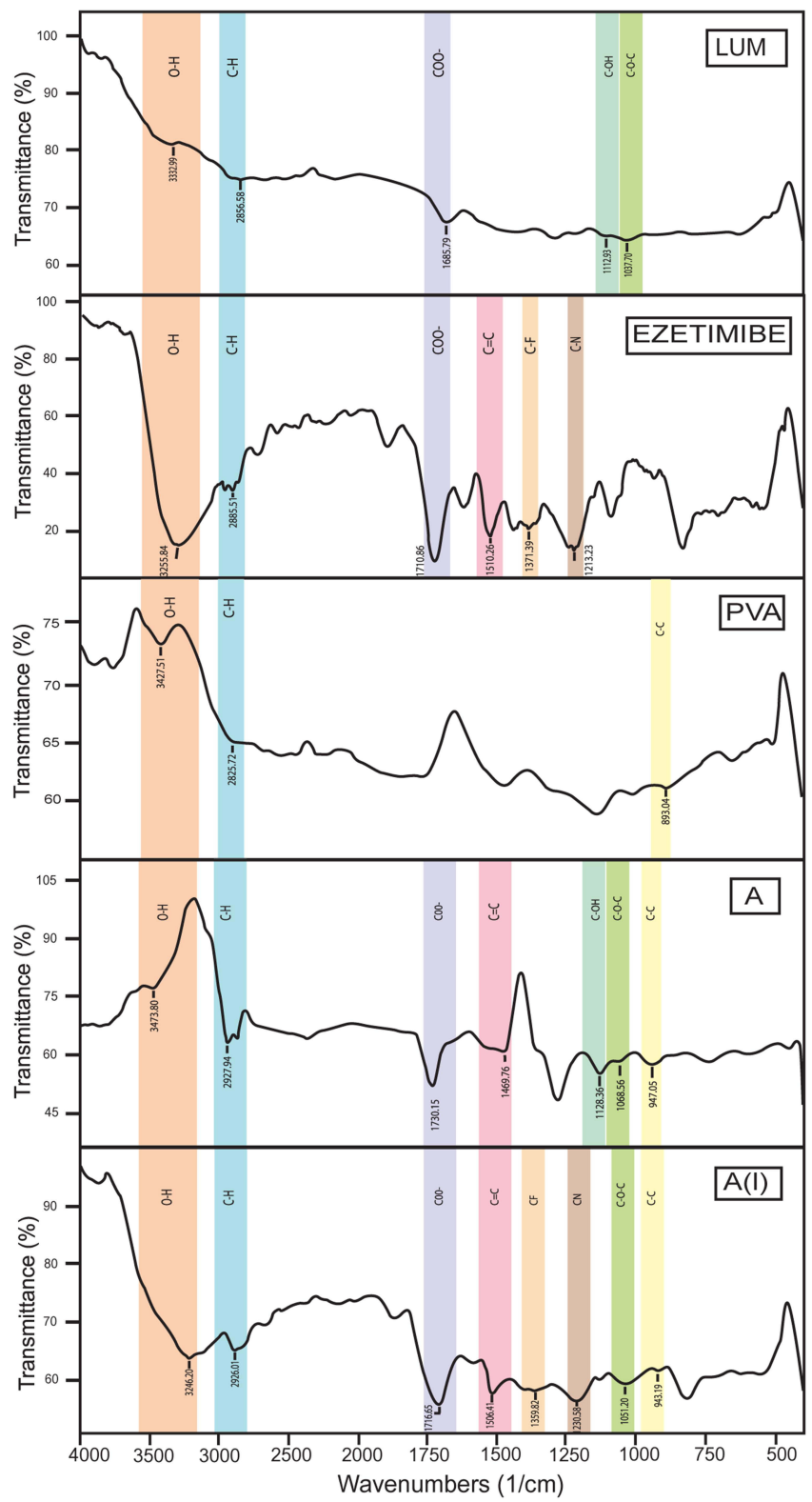

B

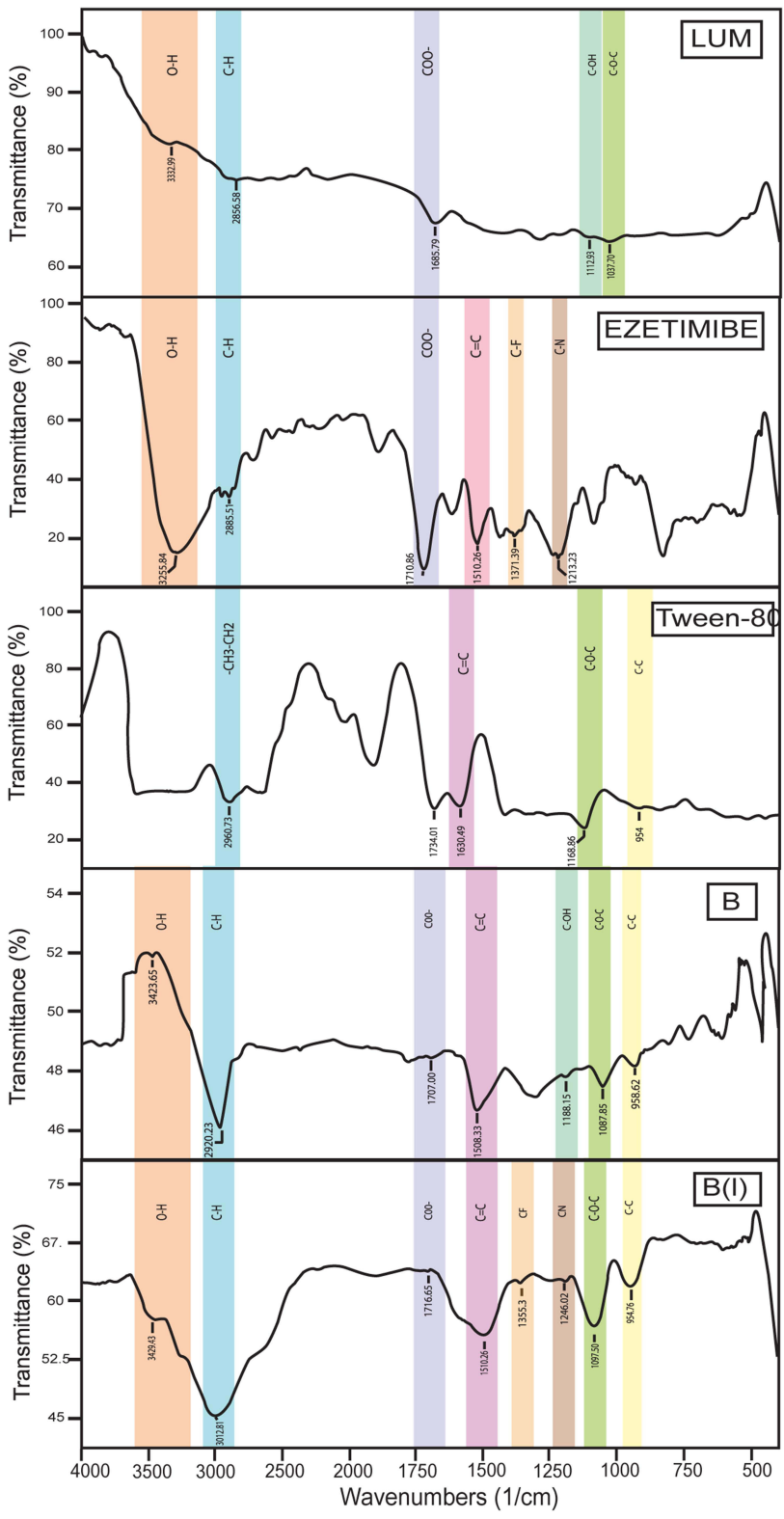

Figure 5 (A) FTIR overlay of LUM, Ezetimibe, PVA, unloaded LUM nanoparticles and Ezetimibe loaded LUM nanoparticles prepared by ESEM (B) FTIR overlay of LUM, Ezetimibe Tween 80, unloaded LUM nanoparticles and Ezetimibe loaded LUM nanoparticles prepared by NPM.

peak at $165^{\circ} \mathrm{C}$ corresponds to the melting point of the drug. When prepared by ESEM (A) and NPM (B), it is evident that the corresponding endothermic peak of the drug in Ezetimibe LUMNs formulations was poorly defined and slightly shifted which indicated amorphization of Ezetimibe and nonexistence in the crystalline state.

Figure 6 also indicates TGA of Ezetimibe, (A) TGA of nanocarriers prepared by ESEM (B) TGA of nanocarriers prepared by NPM. It is evident from the TGA thermogram that both formulations showed three stages of degradation when compared with the drug. Three Steps degradation can be explained as firstly loss of moisture and impurity and secondly carboxylic acid degradation came into account and further. The foundation of stability was attributed due to less water retention and instigate cross linking of mucilage with emulsifying agents during formation. TGA further showed that weight loss up to $280^{\circ} \mathrm{C}$ by both techniques was almost comparable as $12.22 \%$ and $11.21 \%$ with ESEM and NPM respectively. Thermogram of the pure drug indicate that after 


\section{A}

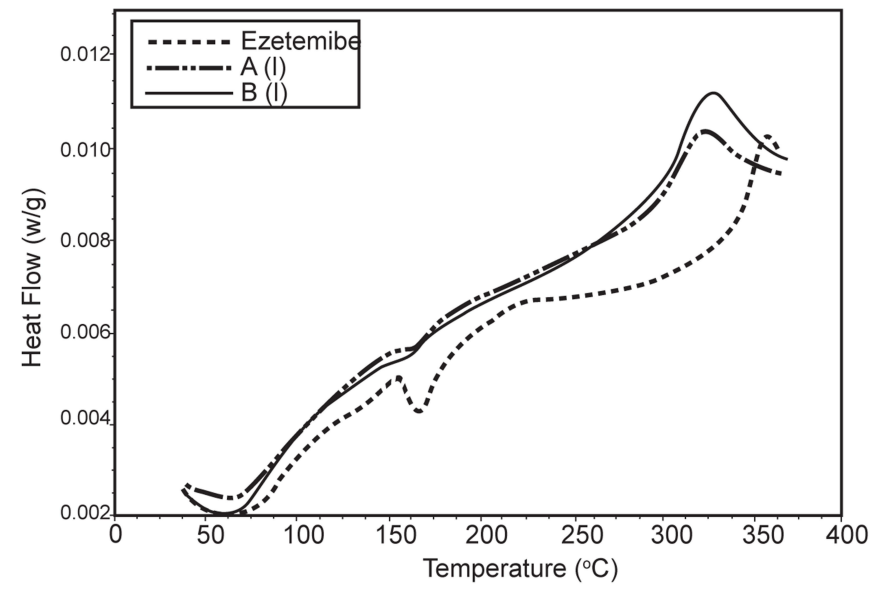

B

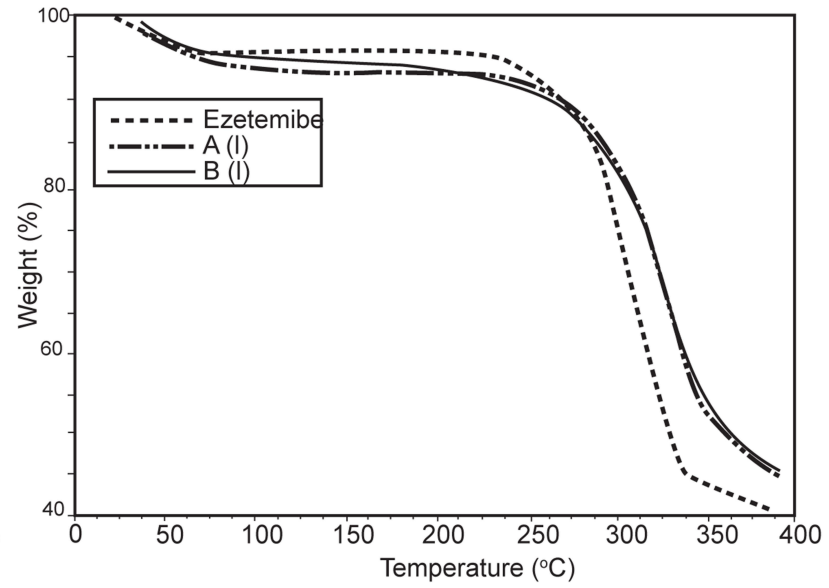

Figure 6 DSC of Ezetimibe, (A) DSC of nanocarriers prepared by ESEM, (B) DSC of nanocarriers prepared by NPM, TGA of Ezetimibe, (A) TGA of nanocarriers prepared by ESEM (B) TGA of nanocarriers prepared by NPM.

melting decomposition of drug starts at $340^{\circ} \mathrm{C}$ but when incorporated in the formulation the decomposition temperature increased up to $15^{\circ} \mathrm{C}$, indicating thermal stability of the fabricated formulations. The residual weights of $47.64 \%$ at $352^{\circ} \mathrm{C}$ and $48.22 \%$ at $356^{\circ} \mathrm{C}$ of ESEM and NPM formulation remained respectively. When two methods were compared, it showed that nanoprecipitation had better stability because the formation of the emulsion during the emulsion evaporation method is sensitive to a higher temperature as it forms a thermodynamically unstable system. ${ }^{52}$ Thermal analysis shows the consensus of findings with PXRD results of this study. ${ }^{53}$

\section{Powder X-Ray Diffraction}

$\mathrm{XRD}$ analysis was employed to determine the physical characteristic and crystallinity of drug-loaded nanocarriers. An overlay of the XRD of Ezetimibe, (A) LUM nanocarriers prepared by ESEM, (B) LUM nanocarriers prepared by NPM is presented in Figure 7. Powder X-ray diffraction pattern of Ezetimibe displayed characteristic sharp peaks at $2 \theta=10.095^{\circ}, 10.105^{\circ}, 21.135^{\circ}, 23.69^{\circ}, 29.86^{\circ}, 36.08^{\circ}$, $40.35^{\circ}, 41.78^{\circ}$, and $44.70^{\circ}$ which confirms its crystalline nature. The drug loaded sample of emulsion evaporation method (A) showed peaks at $2 \theta=10.96^{\circ}, 19.64^{\circ}, 26.42^{\circ}$, and $45.2^{\circ}$. LUM-Ezetimibe nanoparticles prepared by nanoprecipitation presented peaks at $2 \theta=38.77^{\circ}$. Formulations prepared by both methods had a lower intensity and dense diffractograms. The characteristic peaks of Ezetimibe were absent in Ezetimibe LUMNs which signify amorphous dispersion in polymeric nanocarriers with a smaller size. No fingerprint peaks of drug entail that the drug particles had interpenetrated into a polysaccharide network of mucilage. ${ }^{54}$

\section{Scanning Electron Microscopy}

SEM analysis showed that Ezetimibe LUMNs appeared as aggregate in clusters while possessing heterogeneous particle sizes (Figure 8A and B). Ezetimibe loaded nanoparticles prepared by emulsion solvent evaporation method presented a usual spherical like morphology yet slightly rough surface as shown in Figure 8A, moreover among spherical particles solid links can be eminent at greater magnification (Figure 8B). When nanoprecipitation was compared with the emulsion solvent evaporation method the pictogram revealed elongated and denser and very rough surfaces with heterogeneous sizes. Pictorial results of SEM analysis are in agreement with the experimental study in section 3.2 . $^{55}$

\section{Comparative Solubility Studies}

The saturation solubility of pure Ezetimibe was compared with nanoparticle formulations prepared by ESEM and NPM respectively, the p-value observed was 0.000854 and 0.00047 respectively (Figure 9B and C). The fabricated Ezetimibe LUMNs by ESEM and NPM respectively showed a higher level of saturation solubility than individual drug. This employed that solubility of Ezetimibe will be increased by encapsulation in nanoparticles. Thus, this anticipated that the Null hypothesis was rejected because there is a significant difference of solubility among pure Ezetimibe and Ezetimibe-LUMNs formulations prepared by ESEM and NPM (Figure 9). Saturation solubility of 


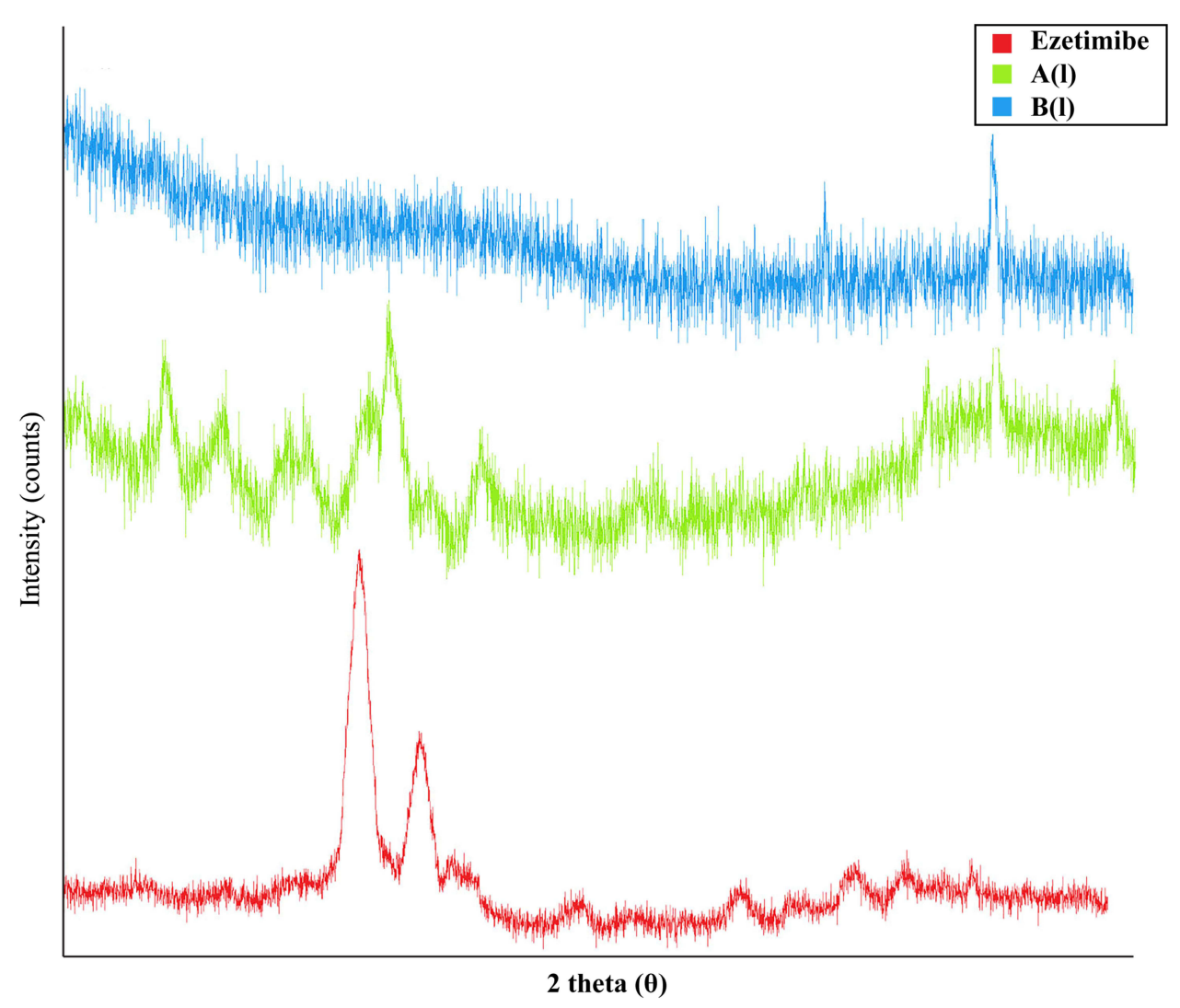

Figure 7 PXRD spectra of Ezetimibe, (A) LUM nanocarriers prepared by ESEM, (B) LUM nanocarriers prepared by NPM.
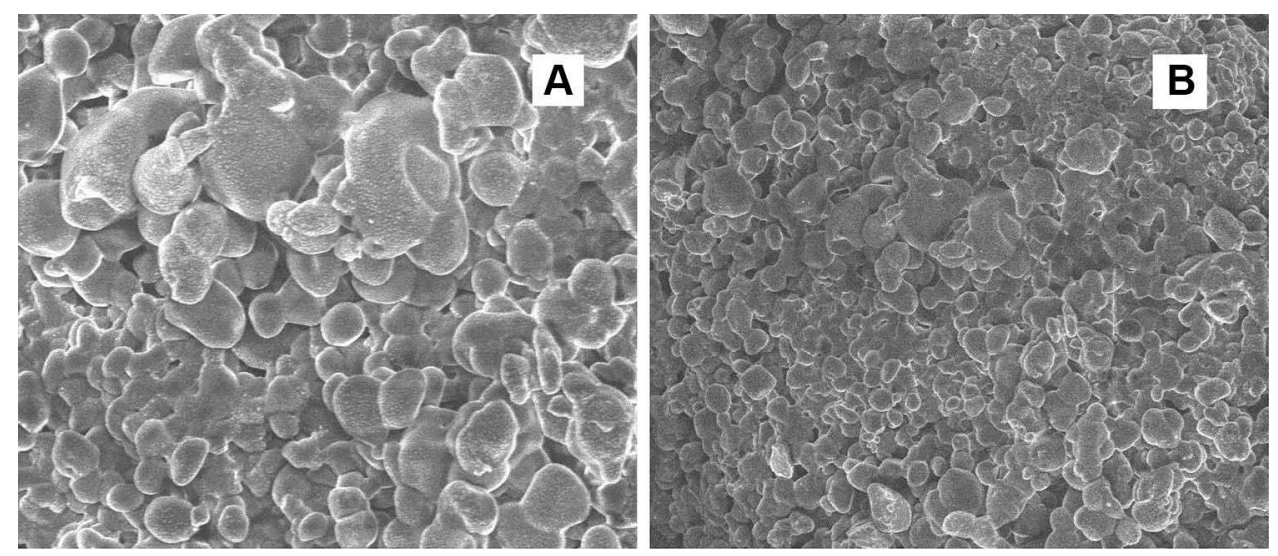

Figure 8 SEM image of (A) LUM nanocarriers prepared by ESEM, (B) LUM nanocarriers prepared by NPM.

LUM-Ezetimibe nanoparticles by NPM technique exhibited a relatively higher level of saturation solubility as compared to ESEM in Figure 9A. This implies enhanced drug solubility in the nanocarrier system due to reduced particle size and crystallinity of drug as proficiently determined by XRD and thermal analysis data. Due to the amorphous structure and reduced size attained by nanocarriers will increase the vapor pressure which in return increases solubility. ${ }^{29}$

\section{In vitro Dissolution Test}

In vitro release studies of LUM-Ezetimibe NPs formulated by emulsion solvent evaporation and NPM at $\mathrm{pH} 6.8$ graphically presented in Figure 10. The dissolution profiles of Ezetimibe LUMNs prepared by ESEM and NPM were determined at $\mathrm{pH} 6.8$ at $37^{\circ} \mathrm{C} \pm 0.5{ }^{\circ} \mathrm{C}$ on the USP dissolution apparatus. Figure 10 represents an extrapolation of Ezetimibe released from LUMN and Table 4 shows release profile data. PNs samples of ESEM and NPM since 


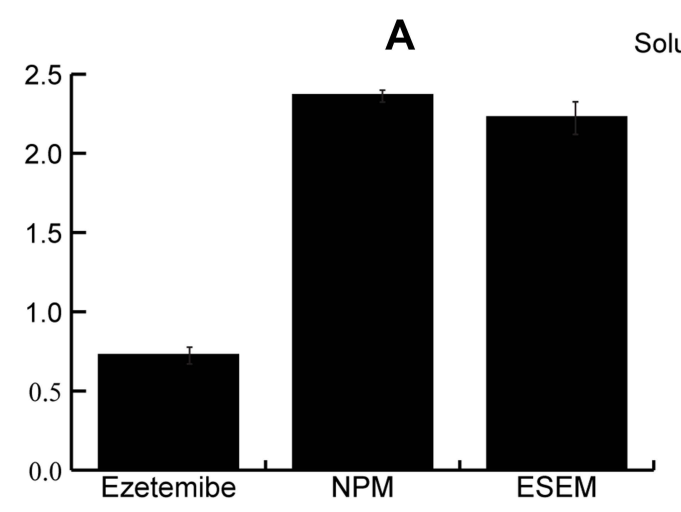

B

C

Figure 9 (A) Saturated solubility study of Ezetimibe, ESEM and NPM nanoparticles (B) Comparative mean solubility of pure Ezetimibe and ESEM nanoparticles (C) Comparative mean solubility of pure Ezetimibe and NPM nanoparticles.

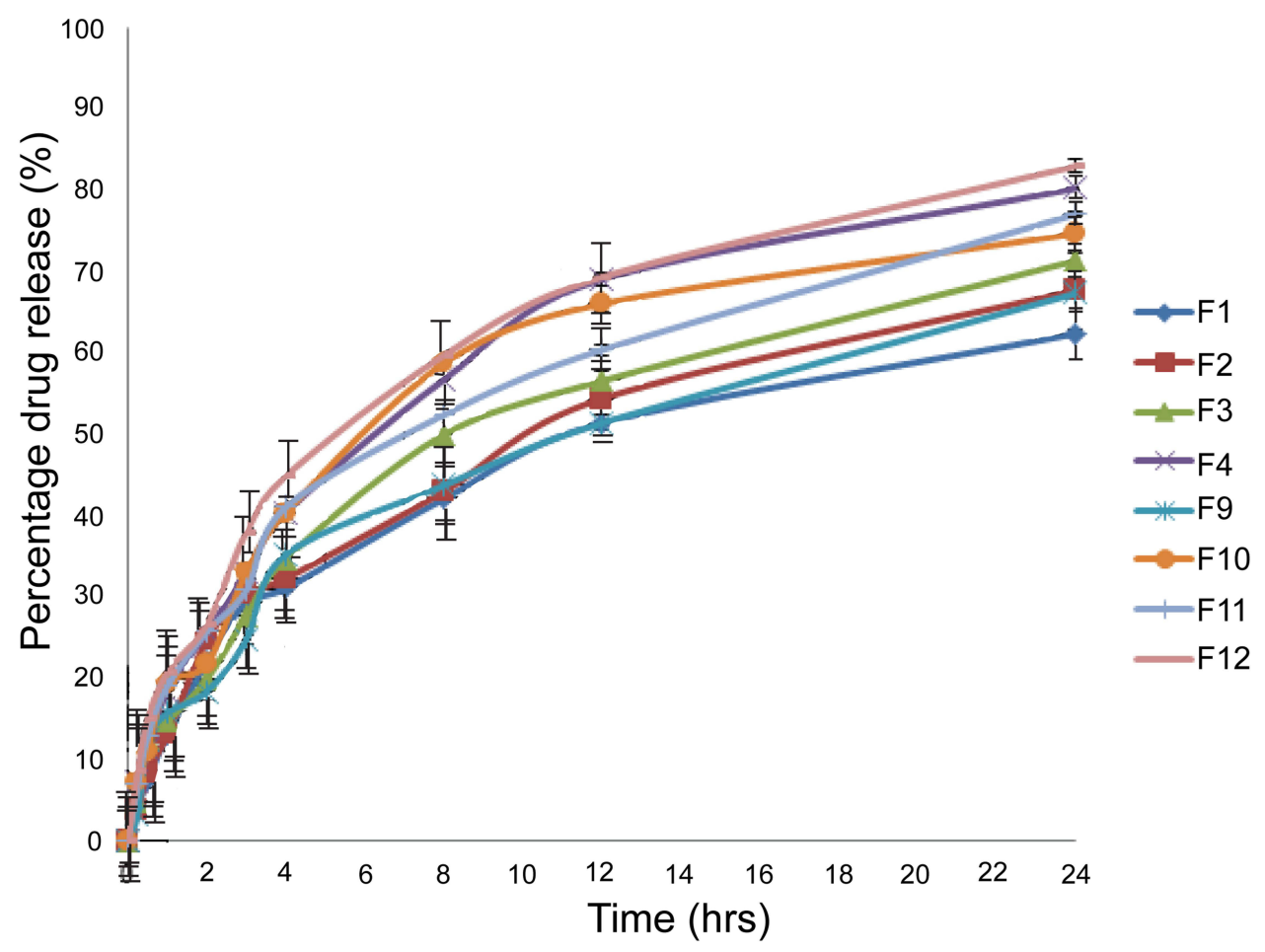

Figure 10 Percentage Ezetimibe release of FI to F4 and F9 to FI2 LUM-Ezetimibe formulation.

both formulations attained a maximum drug dissolved sum of $80.32 \pm 0.1 \%$ and $83.07 \pm 0.8 \%$ respectively at 24 hours. Hasty released was observed at the start which was attributed as the presence of drug at the surface. A similar pattern of release was observed by maximum drug dissolved in 4 hours was up to $45 \%$ and $40 \%$ by NPM and ESEM respectively. ${ }^{12}$

The dissolution test of Ezetimibe LUMNs samples demonstrated an enhancement of in vitro pharmaceutical properties when formulated as a nanocarrier system. The in vitro dissolution profile found to be in agreement with other hydrophobic moieties when fabricated as nanocarrier systems, due to extension of the surface area available led to the improved dissolution of the drug by acquiring prompt saturation in the vessel. The comminution of the hydrophobic drug to the nano-size range is attributable to enlargement in particle curvature, hence increased dissolution pressure observed. The smaller size improved wettability allowed reaching higher saturation concentration of the drug. ${ }^{56}$ In a comparison of both methods, nanoprecipitation showed comparatively better dissolution profile data than ESEM. This implies hydrophobicity of PVA 
Table 4 Correlation Co-Efficient $\left(R^{2}\right)$ and Release Exponent $(n)$ of Various Kinetic Models

\begin{tabular}{|l|l|l|l|l|l|l|}
\hline \multirow{2}{*}{ Formulations } & \multicolumn{3}{|c|}{ Release Models } \\
\cline { 2 - 7 } & Zero order & First order & Higuchi & \multicolumn{2}{l|}{ Korsmeyer-Peppas } & Hixon Crowell \\
\cline { 2 - 7 } & $\mathbf{R}^{\mathbf{2}}$ & $\mathbf{R}^{\mathbf{2}}$ & $\mathbf{R}^{\mathbf{2}}$ & $\mathbf{R}^{\mathbf{2}}$ & $\mathbf{n}$ & $\mathbf{R}^{\mathbf{2}}$ \\
\hline FI & 0.5348 & 0.8267 & 0.9865 & 0.9909 & 0.445 & 0.7505 \\
F2 & 0.5525 & 0.8861 & 0.9892 & 0.9914 & 0.457 & 0.8167 \\
F3 & 0.6658 & 0.9232 & 0.9904 & 0.9918 & 0.497 & 0.8755 \\
F4 & 0.5581 & 0.9444 & 0.9878 & 0.9905 & 0.453 & 0.8964 \\
F9 & 0.7319 & 0.9153 & 0.9899 & 0.9912 & 0.494 & 0.8739 \\
FII & 0.4202 & 0.8703 & 0.9772 & 0.9822 & 0.421 & 0.7916 \\
FI2 & 0.6701 & 0.9447 & 0.9909 & 0.9946 & 0.414 & 0.9010 \\
\hline
\end{tabular}

and also viscous formulation prepared with different concentrations of PVA which are responsible for complex formation with LUM. $^{14}$

\section{Evaluation of Drug Release Kinetics}

Ezetimibe LUMNs release kinetics evaluated with Model dependent approaches (Zero-order Model, First-order Model, Higuchi Model, Korsmeyer-Peppas Model, and Hixon-Crowell Model) are tabulated in Table 5. Correlation coefficient values confirm that drug release kinetics of formulations prepared by ESEM and NPM intently fit the Korsmeyer Peppas Model with R2

Table 5 Clinical Observations of Acute Oral Toxicity Test for LUMNs Formulations

\begin{tabular}{|l|l|l|}
\hline Observations & $\begin{array}{l}\text { Group } \\
\text { I (Control) }\end{array}$ & $\begin{array}{l}\text { Group II (LUMNs } \\
\text { Treated) } \mathbf{5 0 0 0} \mathbf{~ m g / k g / b . w t ~}\end{array}$ \\
\hline Signs of illness & Nil & Nil \\
\hline Body weight (g) & & \\
Pretreatment & $28.5 \pm 3.2$ & $28.3 \pm 4.5$ \\
Day I & $29.8 \pm 3.4$ & $30.4 \pm 1.2$ \\
Day 7 & $30.5 \pm 1.2$ & $33.3 \pm 2.2$ \\
Day I4 & $31.4 \pm 3.1$ & $34.5 \pm 1.9$ \\
\hline Water intake $(\mathrm{mL})$ & & \\
Pretreatment & $8 \pm 1$ & $10 \pm 1.5$ \\
Day I & $8 \pm 1.5$ & $8.5 \pm 1.4$ \\
Day 7 & $10 \pm 1.2$ & $12 \pm 1.3$ \\
Day I4 & $9 \pm 1.3$ & $9.5 \pm 2.5$ \\
\hline Food Intake (g) & & \\
Pretreatment & $5 \pm 0.8$ & $5.5 \pm 1.5$ \\
Day I & $6.6 \pm 0.7$ & $7.5 \pm 0.8$ \\
Day 7 & $7 \pm 1.1$ & $7.6 \pm 1.0$ \\
Day I4 & $7.5 \pm 1.2$ & $8.0 \pm 0.6$ \\
\hline Mortality & $\mathrm{Nil}$ & $\mathrm{Nil}$ \\
\hline
\end{tabular}

$=0.9946$ and Higuchi Model with R2 $=0.9909$ respectively. Higuchi and Korsmeyer-Peppas model were selected on criteria rooted on the bases of the goodness of fit which signifies the correlation coefficient (R2) close to 1 . The multiple release mechanism responsible for active release is erosion, swelling of the polymer matrix, chemical interaction of drug-polymer and diffusion. All formulations were in agreement with the Fick's law. As release exponent values were ranged between $(0.41-0.49)$ and proposed Fickian release and follow the diffusion mechanism while being polydisperse system. The extent of cross linking of LUM is also an important factor other than diffusion. ${ }^{16,57,58}$

\section{Clinical and General Signs of Acute Toxicity}

In acute oral toxicity study, no death was observed over the period of 14 days in both groups. None of the animals showed change in appearance significantly during observation phase. All animals (both controlled and treatment groups) presented insignificant alteration in weight gain when given $5000 \mathrm{mg} / \mathrm{kg}$ dispersion of LUMNs orally (Table 5). All vital organs like liver, kidney, lungs, heart, spleen and stomach were remained unaffected throughout treatment period. The effects of oral intake of LUMNs on body weights, nutrient intake were recorded in Table 5. Physical characteristics of mice were normal and no significant change in behavior was found. Furthermore casual consumption of food and water in the treatment group shows normal physiological status. While conducting the toxicity study neither mortality nor any signs of illness (runny nose, vomiting, salivation and eye irritation) were observed. Pursuant to globally harmonized system (GHS), for testing 
Table 6 Biochemical Blood Analysis of Control and LUMNs Treated Group

\begin{tabular}{|c|c|c|}
\hline $\begin{array}{l}\text { Haematology } \\
\text { and Biochemical } \\
\text { Analysis }\end{array}$ & $\begin{array}{l}\text { Group } \\
\text { I (Control) }\end{array}$ & $\begin{array}{l}\text { Group II (LUMNs Treated) } \\
5000 \mathrm{mg} / \mathrm{kg} / \mathrm{b} . w t\end{array}$ \\
\hline $\mathrm{Hb} g / d L$ & $14.0 \pm 1.1$ & $14.3 \pm 2.5$ \\
\hline WBCs $\times 10^{3} / \mu \mathrm{L}$ & $4.3 \pm 0.5 \mathrm{I}$ & $5.1 \pm 0.88$ \\
\hline RBCsX $10^{6} / \mu \mathrm{L}$ & $8.52 \pm 1.1$ & $8.85 \pm 1.5$ \\
\hline Plateletsx $10^{3} / \mu \mathrm{L}$ & $1319 \pm 2$ & $|08| \pm 6$ \\
\hline Monocytes\% & $\mathrm{I} \pm 0.34$ & $\mathrm{I} \pm 0.45$ \\
\hline Neutrophils\% & $24 \pm 3.95$ & $2 \pm 0.78$ \\
\hline Lymphocytes\% & $96 \pm 3$ & $94 \pm 3.45$ \\
\hline $\mathrm{MCV}$ & $53.5 \pm 3.37$ & $52.4 \pm 2.23$ \\
\hline $\mathrm{MCH}$ & $16.3 \pm 0.19$ & $|7 \pm 0.5|$ \\
\hline $\mathrm{MCHCg} / \mathrm{dl}$ & $30 \pm 0.97$ & $31.8 \pm 0.37$ \\
\hline ALT (IU/I) & $55 \pm 0.19$ & $63 \pm 0.34$ \\
\hline AST (IU/I) & $203 \pm 1.2$ & $246 \pm 1.9$ \\
\hline Creatinine $(\mathrm{mg} / \mathrm{dl})$ & $0.39 \pm 2.23$ & $0.44 \pm 2.23$ \\
\hline Urea $(\mathrm{mg} / \mathrm{dl})$ & $59 \pm 3.06$ & $38 \pm 1.23$ \\
\hline Uric acid (mg/dl) & $3.4 \pm 2.63$ & $4.8 \pm 1.09$ \\
\hline Cholesterol (mg/dl) & $116 \pm 1.3$ & $137 \pm 0.9$ \\
\hline Triglyceride (mg/dl) & $90 \pm 0.23$ & $85 \pm 0.7$ \\
\hline
\end{tabular}

chemicals LD50 value is greater than $2000 \mathrm{mg} / \mathrm{kg}$ dose (category 5) and toxicity score is zero. Therefore, LUMNs formulation was in agreement with category five having zero toxicity score. ${ }^{59}$

\section{Biochemical Blood Analysis}

Blood is the imperative narrator of chemical toxicity produced physiological and pathological conditions. Blood chemistry, kidney, liver and lipid profiles of placebo (control) and treatment group are given in Table 6. The AST and ALT levels presented a little boost, which is valuable indicator of mutilation of liver parenchyma related liver abnormalities. The ALT level of control group was observed to be $55 \mathrm{IU} / \mathrm{L}$ and $63 \mathrm{IU} / \mathrm{L}$ in treatment group, both groups were found in reference range (28-184 IU/L) in mice. Similarly AST value of untreated group was $203 \mathrm{IU} / \mathrm{L}$, while in LUMNs treated group was $246 \mathrm{IU} / \mathrm{L}$. Creatinine, urea as well as lipid profiles were observed in normal range. That indicated no sign of toxicity in blood, liver and kidney of mice.
With no major variation all hematological parameters of untreated and treated groups were in reference range and comparable. $^{60}$

\section{Histopathological Study}

The microscopic evaluation of control and LUMNs treated group disclosed that no histopathological lesions were found in liver, heart, kidney, intestine, stomach and spleen with normal ranged organ weight (Table 7). The myocardium tissues showed optimal integrity (Figure 11). Normal lobular architecture was observed in hepatic parenchyma (Figure 11) but in portal tracts a mild inflammation was revealed. Normal pathology of spleen, stomach mucosa, interstitial mucosa and a mild interstitial inflammation demonstrated no degenerative change (Figure 11). Hence vital organs found to be free from significant pathology.

\section{Conclusion}

Round shaped Ezetimibe LUMNs with size ranged between $416-921 \mathrm{~nm}$ were attained by subjecting Ezetimibe in a polysaccharide network of the mucilage of LUS by emulsion evaporation and NPMs. The pharmaceutical properties and efficacy of ezetimibe were enhanced, and ezetimibe LUMNs confer better solubility furtherance improved dissolution study profile. Nanoprecipitation does better than emulsion solvent evaporation as it consumed less energy, no spare solvent used, more facile, and due to smaller size of Ezetimibe LUMNs confer better solubility. Different assorted concentrations of PVL serve as an imperative aspect that will modulate the pharmaceutical properties of Ezetimibe LUMNs. This work concludes that linseed mucilage is a resourceful alternate to synthetic polymers furtherance can be employed as green polymer-based nanocarriers for the delivery of therapeutic agents. The acute oral toxicological investigations provided evidence that LUMNs were non-toxic, biocompatible and safe after oral administration and a promising candidate for oral drug carrier.

Table 7 Effect of Oral Administration of Hydrogel on the Organ Weight $(\mathrm{Gm})$ of Mice

\begin{tabular}{|l|l|l|l|l|l|l|}
\hline Treatment Groups & Heart & Liver & Lung & Kidney & Stomach & Spleen \\
\hline Control & $0.60 \pm 0.71$ & $6.11 \pm 0.12$ & $0.62 \pm 0.21$ & $0.96 \pm 0.07$ & $1.38 \pm 0.4$ & $0.57 \pm 0.20$ \\
Treatment & $0.53 \pm 0.01$ & $5.70 \pm 0.22$ & $0.49 \pm 0.01$ & $1.20 \pm 0.11$ & $1.6 \pm 0.20$ & $0.89 \pm 0.11$ \\
\hline
\end{tabular}



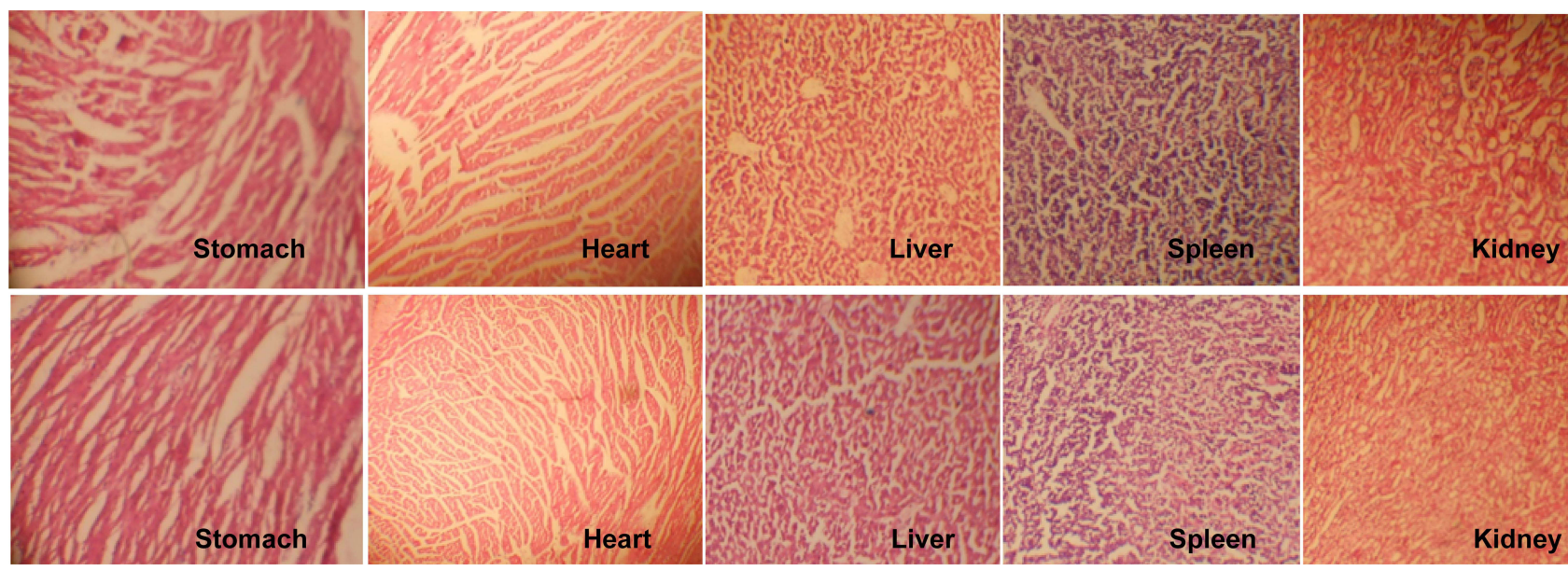

Figure I I Histopathological investigation of control and treated group.

\section{Funding}

This research did not receive any specific grant from funding agencies in the public, commercial, or not-forprofit sectors.

\section{Disclosure}

The authors report no conflicts of interest in this work.

\section{References}

1. Ngwuluka NC, Akanbi M, Agboyo I, Uwaezuoke OJ. Characterization of gum from Sesamum indicum leaves as a suspending agent in a pediatric pharmaceutical suspension. WJPR. 2012;1:909-924.

2. Sonia TA, Sharma CP. An overview of natural polymers for oral insulin delivery. Drug Discov Today. 2012;17(13-14):784-792. doi:10.1016/j.drudis.2012.03.019

3. Ngwuluka NC, Ochekpe NA, Aruoma OI. Naturapolyceutics: the science of utilizing natural polymers for drug delivery. polymers. 2014;6(5):1312-1332. doi:10.3390/polym6051312

4. Elleuch M, Bedigian D, Roiseux O, Besbes S, Blecker C, Attia H. Dietary fibre and fibre-rich by-products of food processing: characterisation, technological functionality and commercial applications: a review. Food Chem. 2011;124(2):411-421. doi:10.1016/j.foodchem.2010.06.077

5. Liu J, Shim YY, Timothy JT, Wang Y, Reaney MJ. Flaxseed gum a versatile natural hydrocolloid for food and non-food applications. Trends Food Sci Technol. 2018;75:146-157. doi:10.1016/j. tifs.2018.01.011

6. Haseeb MT, Hussain MA, Yuk SH, Bashir S, Nauman M. Polysaccharides based superabsorbent hydrogel from Linseed: dynamic swelling, stimuli responsive on-off switching and drug release. Carbohydr Polym. 2016;136:750-756. doi:10.1016/j. carbpol.2015.09.092

7. Haseeb MT, Hussain MA, Abbas K, et al. Linseed hydrogel-mediated green synthesis of silver nanoparticles for antimicrobial and wound-dressing applications. Int J Nanomedicine. 2017;12:2845. doi:10.2147/IJN.S133971

8. Nasrabadi MN, Goli SA, Doost AS, Roman B, Dewettinck K, Stevens CV. Van der Meeren P. Plant based Pickering stabilization of emulsions using soluble flaxseed protein and mucilage nano-assemblies. Colloids Surf a Physicochem Eng Asp. 2019;563:170-182. doi:10.1016/j.colsurfa.2018.12.004
9. Merisko-Liversidge EM, Liversidge GG. Drug nanoparticles: formulating poorly water-soluble compounds. Toxicol Pathol. 2008;36 (1):43-48. doi:10.1177/0192623307310946

10. Patel J, Sheehan V, Gurk-Turner C. Ezetimibe (Zetia): a new type of lipid-lowering agent. Baylor University Medical Center Proceedings; 2003. (Vol. 16, No. 3). Taylor \& Francis. pp. 354-358.

11. Suchy D, Łabuzek K, Stadnicki A, Okopień B. Ezetimibe-a new approach in hypercholesterolemia management. Pharmacol Rep. 2011;63(6):1335-1348. doi:10.1016/S1734-1140(11)70698-3

12. Din F, Zeb A, Shah KU. Development, in-vitro and in-vivo evaluation of ezetimibe-loaded solid lipid nanoparticles and their comparison with marketed product. $J$ Drug Deliv Sci Technol. 2019;51:583-590. doi:10.1016/j.jddst.2019.02.026

13. Kumari A, Yadav SK, Yadav SC. Biodegradable polymeric nanoparticles based drug delivery systems. Colloids Surf B Biointerfaces. 2010;75(1):1-8. doi:10.1016/j.colsurfb.2009.09.001

14. Alshamsan A. Nanoprecipitation is more efficient than emulsion solvent evaporation method to encapsulate cucurbitacin I in PLGA nanoparticles. Saudi Pharm J. 2014;22(3):219-222. doi:10.1016/j. jsps.2013.12.002

15. Hornig S, Heinze T, Becer CR, Schubert US. Synthetic polymeric nanoparticles by nanoprecipitation. J Mater Chem. 2009;19 (23):3838-3840. doi:10.1039/b906556n

16. Haseeb MT, Khaliq NU, Yuk SH, Hussain MA, Bashir S. Linseed polysaccharides based nanoparticles for controlled delivery of docetaxel: design, in vitro drug release and cellular uptake. J Drug Deliv Sci Technol. 2019;49:143-151. doi:10.1016/j.jddst.2018. 11.009

17. Song X, Zhao Y, Wu W, et al. PLGA nanoparticles simultaneously loaded with vincristine sulfate and verapamil hydrochloride: systematic study of particle size and drug entrapment efficiency. Int J Pharm. 2008;350(1-2):320-329. doi:10.1016/j.ijpharm.2007. 08.034

18. Nosrati H, Adinehvand R, Manjili HK, Rostamizadeh K, Danafar H. Synthesis, characterization, and kinetic release study of methotrexate loaded MPEG-PCL polymersomes for inhibition of MCF-7 breast cancer cell line. Pharm Dev Technol. 2019;24(1):89-98. doi:10.1080/ 10837450.2018.1425433

19. Malviya J, Joshi V, Singh K. Antimicrobial activity of some ethno-medicinal plants used by Baiga Tribes from Amarkantak, India. Adv Life Sci Technol. 2012;4:19-26.

20. Farooq U, Malviya R, Sharma PK. Extraction and characterization of okra mucilage as pharmaceutical excipient. Acad J Plant Sci. 2013;6 (4):168-172. doi:10.5829/idosi.ajps.2013.6.4.82292 
21. Meva FE, Ntoumba AA, Kedi PB, et al. Silver and palladium nanoparticles produced using a plant extract as reducing agent, stabilized with an ionic liquid: sizing by X-ray powder diffraction and dynamic light scattering. J Mater Res Tech. 2019;8(2):1991-2000. doi:10. 1016/j.jmrt.2018.12.017

22. Ali SW, Rajendran S, Joshi M. Synthesis and characterization of chitosan and silver loaded chitosan nanoparticles for bioactive polyester. Carbohydr Polym. 2011;83(2):438-446. doi:10.1016/j. carbpol.2010.08.004

23. Hussein-Al-Ali SH, Kura A, Hussein MZ, Fakurazi S. Preparation of chitosan nanoparticles as a drug delivery system for perindopril erbumine. Polym Compos. 2018;39(2):544-552. doi:10.1002/pc.23967

24. Agel MR, Baghdan E, Pinnapireddy SR, Lehmann J, Schäfer J, Bakowsky U. Curcumin loaded nanoparticles as efficient photoactive formulations against gram-positive and gram-negative bacteria. Colloids Surf B Biointerfaces. 2019;178:460-468. doi:10.1016/j. colsurfb.2019.03.027

25. Sathish S, Kumaresan K, Prabhu L, Vigneshkumar N. Experimental investigation on volume fraction of mechanical and physical properties of flax and bamboo fibers reinforced hybrid epoxy composites. Polym Polym Compos. 2017;25(3):229-236. doi:10.1177/096739 111702500309

26. Algul D, Duman G, Ozdemir S, Acar ET, Yener G. Preformulation, characterization, and in vitro release studies of caffeine-loaded solid lipid nanoparticles. J Cosmet Sci. 2018;69(3):165-173.

27. Parveen S, Wani AH, Shah MA, Devi HS, Bhat MY, Koka JA. Preparation, characterization and antifungal activity of iron oxide nanoparticles. Microb Pathog. 2018;115:287-292. doi:10.1016/j. micpath.2017.12.068

28. Yeole BD, Patil RP, Lone KD, Tekade AR. Preparation of nanoparticles of poorly water soluble dronedarone by antisolvent addition technique using natural polymer as a stabilizer. J Pharm Res Clin Pract. 2016;6(4):8-16.

29. Fabre HS, Fabre S, Cefaly DF, de Oliveira Carrilho MR, Garcia FC, Wang L. Water sorption and solubility of dentin bonding agents light-cured with different light sources. J Dent. 2007;35 (3):253-258. doi:10.1016/j.jdent.2006.09.002

30. Kumar SS. Formulation and characterization of noscapine-loaded polycaprolactone nanoparticles. Asian J Pharm. 2019;13:01.

31. Holowka EP, Bhatia SK. Controlled-release systems. In: Drug Delivery. New York, NY: Springer; 2014:7-62.

32. Chen X, Qian Z, Gou M, et al. Acute oral toxicity evaluation of biodegradable and $\mathrm{pH}$-sensitive hydrogel based on polycaprolactone, poly (ethylene glycol) and methylacrylic acid (MAA). J Biomed Mater Res A. 2008;84(3):589-597. doi:10.1002/jbm.a.31350

33. Fabre HSC, Fabre S, Cefaly DFG, de Oliveira Carrilh MR, Garcia FCP, Wang L. Water sorption and solubility of dentin bonding agents light-cured with different light sources. Journal of dentistry. 2007;35(3):253-258.

34. Dzuvor CK, Taylor JT, Acquah C, Pan S, Agyei D. Bioprocessing of functional ingredients from flaxseed. Molecules. 2018;23(10):2444. doi:10.3390/molecules23102444

35. Besumbes ES, Fornaguera C, Monge M, et al. PLGA cationic nanoparticles, obtained from nano-emulsion templating, as potential DNA vaccines. Eur Polym J. 2019;120:109229. doi:10.1016/j.eurpolymj.20 19.109229

36. Yadav RNS, Agarwala M. Phytochemical analysis of some medicinal plants. J Phytol. 2011;3:12.

37. Luque-Alcaraz AG, Lizardi-Mendoza J, Goycoolea FM, HigueraCiapara I, Argüelles-Monal W. Preparation of chitosan nanoparticles by nanoprecipitation and their ability as a drug nanocarrier. $R S C A d v$. 2016;6(64):59250-59256. doi:10.1039/C6RA06563E

38. Sharma N, Madan P, Lin S. Effect of process and formulation variables on the preparation of parenteral paclitaxel-loaded biodegradable polymeric nanoparticles: a co-surfactant study. Asian J Pharm Sci. 2016;11(3):404-416. doi:10.1016/j.ajps.2015.09.004
39. Sahoo SK, Panyam J, Prabha S, Labhasetwar V. Residual polyvinyl alcohol associated with poly (D, L-lactide-co-glycolide) nanoparticles affects their physical properties and cellular uptake. J Control Release. 2002;82(1):105-114. doi:10.1016/S0168-3659(02)00127-X

40. Zahr AS, Davis CA, Pishko MV. Macrophage uptake of core- shell nanoparticles surface modified with poly (ethylene glycol). Langmuir. 2006;22(19):8178-8185. doi:10.1021/la060951b

41. Li X, Qin Y, Liu C, Jiang S, Xiong L, Sun Q. Size-controlled starch nanoparticles prepared by self-assembly with different green surfactant: the effect of electrostatic repulsion or steric hindrance. Food Chem. 2016;199:356-363. doi:10.1016/j.foodchem.2015.12.037

42. Stolnik S, Dunn SE, Garnett MC, et al. Surface modification of poly (lactide-co-glycolide) nanospheres by biodegradable poly (lactide)-poly (ethylene glycol) copolymers. Pharm Res. 1994;11 (12):1800-1808. doi:10.1023/A:1018931820564

43. Redhead HM, Davis SS, Illum L. Drug delivery in poly (lactide-coglycolide) nanoparticles surface modified with poloxamer 407 and poloxamine 908: in vitro characterisation and in vivo evaluation. $J$ Control Release. 2001;70(3):353-363. doi:10.1016/S01683659(00)00367-9

44. Yu X, Lee JK, Liu H, Yang H. Synthesis of magnetic nanoparticles to detect Sudan dye adulteration in chilli powders. Food Chem. 2019;299:125144. doi:10.1016/j.foodchem.2019.125144

45. Gadad AP, Dandagi PM, Mastiholimath VS. Moxifloxacin loaded polymeric nanoparticles for sustained ocular drug delivery. Int J Pharm Sci Nanotech. 2012;5(2):1727-1734. doi:10.37285/ ijpsn.2012.5.2.8

46. Zambaux MF, Bonneaux F, Gref R, et al. Influence of experimental parameters on the characteristics of poly (lactic acid) nanoparticles prepared by a double emulsion method. J Control Release. 1998;50 (1-3):31-40. doi:10.1016/S0168-3659(97)00106-5

47. Lee SC, Oh JT, Jang MH, Chung SI. Quantitative analysis of polyvinyl alcohol on the surface of poly (D, L-lactide-co-glycolide) microparticles prepared by solvent evaporation method: effect of particle size and PVA concentration. J Control Release. 1999;59 (2):123-132. doi:10.1016/S0168-3659(98)00185-0

48. Emaga TH, Rabetafika N, Blecker CS, Paquot M. Kinetics of the hydrolysis of polysaccharide galacturonic acid and neutral sugars chains from flaxseed mucilage. BASE; 2012.

49. Oomah BD, Kenaschuk EO, Cui W, Mazza G. Variation in the composition of water-soluble polysaccharides in flaxseed. J Agric Food Chem. 1995;43(6):1484-1488. doi:10.1021/jf00054a013

50. Qian KY, Cui SW, Wu Y, Goff HD. Flaxseed gum from flaxseed hulls: extraction, fractionation, and characterization. Food Hydrocoll. 2012;28(2):275-283. doi:10.1016/j.foodhyd.2011.12.019

51. Rashid R, Kim DW, Yousaf AM, et al. Comparative study on solid self-nanoemulsifying drug delivery and solid dispersion system for enhanced solubility and bioavailability of ezetimibe. Int J Nanomedicine. 2015;10:6147. doi:10.2147/IJN.S91216

52. Gopalasatheeskumar K, Komala S, Mahalakshmi M. An overview on polymeric nanoparticles used in the treatment of diabetes mellitus. PharmaTutor. 2017;5(12):40-46. doi:10.29161/PT.v5. i12.2017.40

53. Mello VA, Ricci-Júnior E. Encapsulation of naproxen in nanostructured system: structural characterization and in vitro release studies. Quim Nova. 2011;34(6):933-939. doi:10.1590/S0100-40422011000600004

54. Thakre N, Khatri K, Shilpi S. Development and characterization of solid dispersion of Ezetimibe by using solvent evaporation method. Asian J Pharm Pharmacol. 2016;2(2):44-49.

55. Jyoti K, Baunthiyal M, Singh A. Characterization of silver nanoparticles synthesized using Urtica dioica Linn. leaves and their synergistic effects with antibiotics. J Radiat Res Appl Sci. 2016;9(3):217-227. doi:10.1016/j.jrras.2015.10.002

56. Mauludin R, Müller RH, Keck CM. Development of an oral rutin nanocrystal formulation. Int $J$ Pharm. 2009;370(1-2):202-209. doi:10.1016/j.ijpharm.2008.11.029 
57. Ritger PL, Peppas NA. A simple equation for description of solute release I. Fickian and non-fickian release from non-swellable devices in the form of slabs, spheres, cylinders or discs. $J$ Control Release. 1987;5(1):23-36. doi:10.1016/0168-3659(87) 90034-4

58. Saurí J, Millán D, Suñé-Negre JM, et al. Quality by design approach to understand the physicochemical phenomena involved in controlled release of captopril SR matrix tablets. Int J Pharm. 2014;477(12):431-441. doi:10.1016/j.ijpharm.2014.10.050
59. Maneewattanapinyo P, Banlunara W, Thammacharoen C, Ekgasit S, Kaewamatawong T. An evaluation of acute toxicity of colloidal silver nanoparticles. J Vet Med Sci. 2011;1106220557. doi:10.1292/ jvms.11-0038

60. Singh T, Sinha N, Singh A. Biochemical and histopathological effects on liver due to acute oral toxicity of aqueous leaf extract of Ecliptaalba on female Swiss albino mice. Indian J Pharmacol. 2013;45(1):61. doi:10.4103/0253-7613.106437

\section{Publish your work in this journal}

The International Journal of Nanomedicine is an international, peerreviewed journal focusing on the application of nanotechnology in diagnostics, therapeutics, and drug delivery systems throughout the biomedical field. This journal is indexed on PubMed Central, MedLine, CAS, SciSearch ${ }^{\mathbb{R}}$, Current Contents ${ }^{\mathbb{R}} /$ Clinical Medicine, $^{-}$
Journal Citation Reports/Science Edition, EMBase, Scopus and the Elsevier Bibliographic databases. The manuscript management system is completely online and includes a very quick and fair peer-review system, which is all easy to use. Visit http://www.dovepress.com/ testimonials.php to read real quotes from published authors. 